\title{
Economic Aspects of the Transformational Industries (TI) An Evaluation Study of Sudanese (TI) during (2004/2005 up to 2013/2014)
}

\author{
Ayoub Taha Sidahmed Taha ${ }^{1}$ \\ ${ }^{1}$ Assistant professor of economics- SIU, Khartoum, Sudan. \\ Correspondence: Ayoub Taha Sidahmed Taha, Assistant professor of economics- SIU, Khartoum, Sudan.
}

Received: February 14, 2016

Accepted: March 15, 2016

Available online: March 22, 2016

doi:10.11114/aef.v3i3.1478

URL: http://dx.doi.org/10.11114/aef.v3i3.1478

\begin{abstract}
This study evaluates the performance of transformational industries (TI) in Sudan during the period (2004/2005 up to 2013/2014). This period represents the terminal point of the Comprehensive National Strategy, the period of the Five-Year plan and the beginning of the second Five-Year Plan of the Quarter-Century Strategy (2007/2008-2031/2032). This period is therefore appropriate for achieving indicators that provide evidence for the economic impact of this industry.

This study aims to discuss the economics of (TI) from various aspects. Accordingly, the study adopts the descriptive analytical method that acknowledges the structure and the strategies related to the (TI), and clarifies TI's economic role. The descriptive analytical method assesses the impact of (TI) on the GDP, the contribution of the export sector and the deficit in the balance of trade. To support its findings, the study draws comparisons between (TI) performance in Sudan and that in other countries.
\end{abstract}

The most prominent findings of this study are:

The (TI) contribution to the value added of products is low, with an average share in GDP around 10.5\%. In addition, the (TI) average share in exports is about $0.24 \%$, whereas the average share of imports from (TI) products is around $41.35 \%$. This indicates that (TI) is not supporting the balance of trade, which explains the weak competitiveness of Sudanese (TI) relative to other countries in the region. Such findings are in agreement with the International Index of Specialization (IIS) data.

The study confirms that (TI) in Sudan faces, some problems related to TI structure (locality, concentration, and size of industry) and (TI) types. Moreover, the financial and investment policies are focused on small and medium scale industries without the due attention to (TI).

TI therefore failed to achieve the value added of its products or increase employment opportunities. The study also reveals that the infrastructure of (TI) did not consider the detrimental effects of the industry on the environment.

The policies of some productive sectors negatively affected (TI). For instance, the edible oil and textile industries have been adversely affected by the introduction of wheat in place of cotton in the Gezira Scheme. In conclusion, the study made some recommendations to revive the (TI) in Sudan. It is important to improve the quality of (TI) products to gain competitive advantage. Large-scale industries must also be established and agglomerated in such a way that encourages forward, backward and vertical integration. An investment map should be designed consistent with the availability of resources' of each region. It is necessity that regulations and administrative structures should put in place to improve performance.

Keywords: Transformational industries ( TI) ,economic role ,value added ,strategy

\section{Introduction}

\subsection{Study plan}

The (TI) has gained importance because of its effective role as stimulator to production by diversification of sources of income and best utilization of material and human resources. In addition, (TI) is an essential tool for solving some structural economic problems. Therefore, the study tries to explore the economic aspects of transformational industries (TI) by explaining the concept and identifying its strategies and importance to the economies. Within this context, the 
study evaluates the economic contribution of (TI) on the Sudanese economy.

\subsection{Study problem}

The issue of industrialization is becoming increasingly complicated within the international changes in areas of economical and political life, as well as the rapid advances in technology and communication. In the frame of these changes that affect the (TI) economics, the study tries to evaluate the role and contribution of (TI) in the Sudanese economy.

\section{Study hypothesis}

a) There is a significant relation between the Sudanese (TI) structure and its economic performance.

b) There is a significant relation between Sudanese (TI) value added and its share in the GDP.

c) There is a significant relation between Sudanese (TI) products and its share in the Balance of trade.

\subsection{Study importance}

The study draws its importance from the worth of (TI) sector, which now occupies a prominent position in the decision making in countries that seek to achieve a balanced economic growth, increased job opportunities, ample supply of commodities, and fulfillment of the local demand and support of the GDP.

\subsection{Study objectives}

The objectives are to:

a) Explain some issues related to the economic theory of (TI)

b) Evaluate the contribution of (TI) in the Sudanese GDP.

c) Estimate the share of (TI) in the Sudanese balance of trade.

d) Discuss the policies that related to the (TI).

\section{Methodology}

To achieve the above objectives, the study adopted the descriptive analytical approach to explain the theoretical issues related to the (TI) economics \& policies . On the other hand, the descriptive statistical analysis used to show the (TI) economic contribution.

Study Span:

The study covers the period between (2004/2005 up to 2013/2014). This period represents the final findings of the national comprehensive plan and elapsing of the first third of the quadrant-century strategy (2007/2008-2031/3032) which are important for the (TI) study.

Study Structure

(A) Transformational industries (TI) economics:

1. The concept and Importance of industry in the economy

1.1. Importance of (TI) industry in the economy

1.2. Industrialization strategy

(B) Economic role of Transformational industry (TI) in Sudan:

2. The structure of Sudanese Transformational industry (TI)

3. Economic contribution of Sudanese (TI)

3.1. (TI) Share In industrial value added and in the gross domestic product (GDP)

3.2. (TI) share in exports and imports -Balance of trade-(BOT)

4. Sudanese transformational Industries (TI) strategies and problems

4.1. (TI) strategies in Sudan

4.2. The factors that led to minimal economic share of Sudanese (T .Industries)

5. Conclusion

5.1. Results

5.2. Recommendations.

(A) Transformational industries (TI) economics: 
The concept and importance of industry in the economy:

The industrial units from economic point of view are the primary units within which productive resources are organized for producing wealth. However, the industrial economists tried to use different ways to define the industrial units, depending on the type of products, size of production and production processes ...i.e. . . (The industry in theory is conceived as an aggregate of firms producing identical products in the physical make-up and in the attitudes of consumers towards them.) 1 .But the Difficulty of identifying the concept of the industrial unit relates to the following controversial issues:-

- It is quite usual for the single firm to produce a wide variety of products for example; a factory may produce clothes from leather materials and from cotton, then how to classify this productive unit? Is it right to consider it under the title of textile industry or leather industry?

- The nature of the activity is difficult to be identified, for example is it right to say that the collection of parts of certain commodity (industrial activity) or the industrial activity is (only) related to the processing of transformation of inputs to outputs? This point is very important because in lot countries like Sudan there increase of numbers of firms that specialize in aggregation of finished units.

- The nature of commodities makes it difficult to classify them from an industrial point of view, (The leather products industry, which uses leather materials classified as leather industry from the supply side. However, from the demand side, the activity of leather clothes is classified within the ready-made clothes industry $)^{2}$.

- Accordingly, as far as the characteristics of commodities are different in quality, it becomes difficult from the consumer point of view, to group such commodities under one industrial title. For differentiation, the substitutability criterion which depend on the cross elasticity of demand is used (percentage $\Delta$ of Qdx/ percentage $\Delta$ of Py). Whenever the cross elasticity between (x) and(y) is positive then the two commodities are substitutes for each other, and can be grouped under one title of industry. For example, Kisra (a popular meal in Sudan made from durra) and bread production both are considered under the title of (Bakery industry).

Also products can be classified according to the consumption style, using digit system of classification, for example all consumptive items used for food are called (food industries) and denoted by digit example (31 two digit ).etc

\subsection{Importance of (TI) industry in economies similar to Sudanese economy}

Support revenues from the foreign currency through import substitutes or export oriented industries. This policy is based on the premise that a country should attempt to reduce its foreign dependency through local production of goods, mainly industrial products. Some scholars do not support such policy as it may create inefficient and obsolete products which are not exposed to international competition. The more a country is industrialized, the more it needs imports and import substitution industrialization (ISI) which is strongly biased against exports.) $)^{3}$. However, in my view for a country like Sudan, which is an agricultural country, such policy did not hinder the production but caused impressive gains in food production.

The industrial sector is characterized by increasing marginal productivity (MP), so it mitigates disguised and open unemployment, this point had been emphasized in Lewis analysis model (disguised unemployment in agriculture, positing a zero marginal product of labor ${ }^{4}$ therefore relatively increasing high-productivity employment opportunities outside the agricultural sector like industrial sector which will absorb the low-income agricultural population.

The industrial sector is able to attain increasing marginal productivity through:

A. Using advanced technology, which increases productivity.

B. In the industrial sector the factors of production are flexible.

C. Division of labor in industrial sector increases labor productivity especially in large-scale production.

D. The industrial sector is able to diversify production base and mitigates risks.

E. It offers comparative advantage through utilization of the economic resources.

a) Industrial sector attract labor force from agricultural sector, accordingly increases productivity in agricultural sector through minimizing the pressure of disguised unemployment. At the same time the surplus labor force contributes in expanding the industrial production, and because their income increases this will push the

\footnotetext{
1 A.Beacham- .Economics of industrial organization, Sir Isaac Pitman and sons p 1 London third edition 1956

2 Ahmed saeed Bakhirma. Industrial economics , Dar Alzhra for publishing p 16 , Riyadh, Saudi Arabia $2^{\text {nd }}$ edition 2001

Nimal Sanderatne-The Sunday Times Economic Analysis-Sunday -November 06/2011 Sunday November 06, 2011

4 Title: Trade and Employment in Developing Countries, Volume 3:Synthesis and Conclusions Volume Author/Editor: Anne O. Krueger Publisher: University of Chicago Press Volume ISBN: 0-226-45495-9 p 3-1983
} 
aggregate demand upward. (Manufacturing is an engine of economic growth as industrial goods have a higher-income elasticity of demand $)^{5}$

b) The industry is an effective sector that contributes to the development through forward linkages (supply raw material to other industries) and backward linkages (to demand its needs from other sectors). Industries with strong backward and forward linkages are termed as key sectors since they play an important role in the development strategy of a country.

The sum of the backward linkage effect and the forward linkage effect gives the total linkage effect, which is manifested as growth in new industries induced from establishing an industry. Hirschman was careful on the issue of backward linkages: he noted that (linkages between parent and satellite industries are unlikely to be as important as those formed with larger industries that have a lower probability of forming $)^{6}$

\subsection{Industrialization strategies}

The definition of industrial strategy is a controversial issue. Some scholars concentrate on ownership, others concentrate on types of products and some on restriction or expansion of production. The common target, however, is to build a strategy through a coherent set of policies capable of achieving industrial development and large industrialization capacity.

(A) Ownership of industrial projects strategy:

This indicates the legal rights of possession. Accordingly, some industrial projects are owned by private sector while others are owned by the state. The state ownership is determined by certain economic factors as in the following projects:

a) Large scale projects which require intensive capital such as the iron and petrochemical industries.

b) Noncommercial profit projects specially in the short run.

c) Society oriented projects such as capacity building projects.

d) Public utilities projects that are characterized by cost diminishing, more consumers and less cost where the ownership should be by one owner (natural monopoly). Such projects exemplified by the production and distribution of electricity.

(B) Strategy, related to the type of industry:

There are different views considering the strategy, which should be adopted towards the selection of the types of industries. Some states encourage small-scale industries, while others encourage heavy industries. However, the principal factors that influence this selection are ${ }^{7:}$

a) Market size: heavy industries unlike light industries require a large market for the distribution of its products to minimize the overhead costs as far as possible.

b) The size and composition of the labor force: well-trained and skilled laborers encourage establishment of heavy industries.

c) Capital size: this depends on the minimum level of marginal efficiency of firms productivity (MEP), the size where (AC) of production reach minimum level. This level needs much capital for investment in heavy industry.

d) Availability of raw materials: encourages establishment of heavy industry

e) Infrastructure: is essential for the establishment of industry particularly heavy industries.

(C) Targeted market with industrial products strategy:

The industrialization strategy of a certain state may be import-oriented toward producing import substitutes or export-oriented, producing products for export.

Usually import substitute strategy depends on the following:-

a) Production of local products identical to the imported ones to, reduce the marginal rate of importation (MRI). MRI $=(\Delta$ in total volume of imports from $\mathrm{x} / \Delta$ In income $)$.

b) Imposition of high custom duties, on imported commodities to protect the local ones.

\footnotetext{
${ }^{5}$ Kaldor, N. (1967), Strategic factor in economic development, New York: New York State School of Industrial-p 37 USA

6 Amy Jocelyn Glass, Vasilios D. Kosteas, and Kamal Saggi- LINKAGES, MULTINATIONALS AND INDUSTRIAL DEVELOPMENT

Mohamed Mahros Ismail -ibid -page 40-41 -1987
} 
c) Encouragement of foreign capital to invest in the local industrial projects.

The merits of this strategy can be summarized as follows:

a) Increase in the reserves of hard currency. through the effective protection rate(EPR) which reflect increase in the value added of locally produced items within local industry under protection and without protection $. \mathrm{EPR}=\mathrm{V}$. added of Under protection $-\mathrm{V}$. added of $\mathrm{X}$ with no protection/ V. added of $\mathrm{X}$ with no protection)

b) Create employment chances for the local labor force.

c) Benefiting from already exist import commodities markets before the adoption of customs protection policy i.e. the infant industries will find the chance to market its products.

d) increase the return from local resources utilized in production of local commodities to generate foreign currency

Demerits of this strategy can be summarized as follows:

More protection may discourage infant industries in the absence of competition with foreign industries. Under this situation some types of monopolies may emerge for certain industries

(A) Case (1)

Slope of demand curve (AR) is steeply, so high cost high price

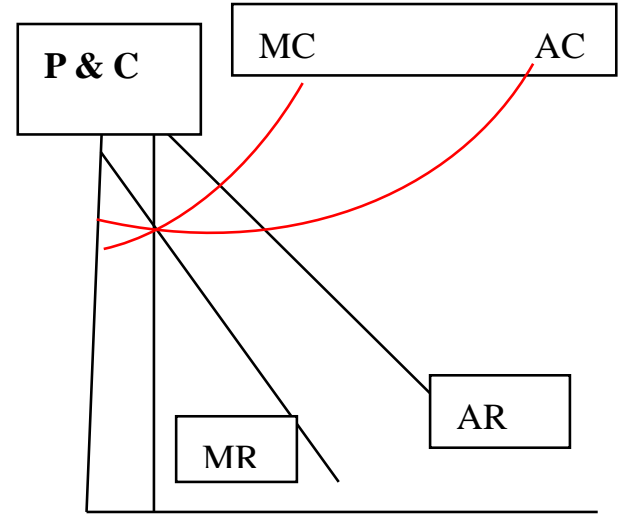

Source: The researcher

(B) Case (2)

Slope of Demand curve (AR) is less steeply so less cost and price than (A)

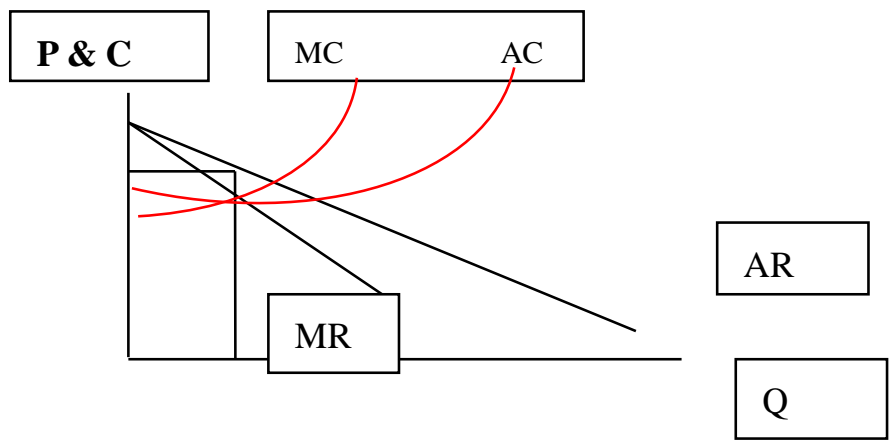

Source: The researcher 
(C) Case (3)

Slope of Demand curve (AR) is less steeply so less cost and price than (B)

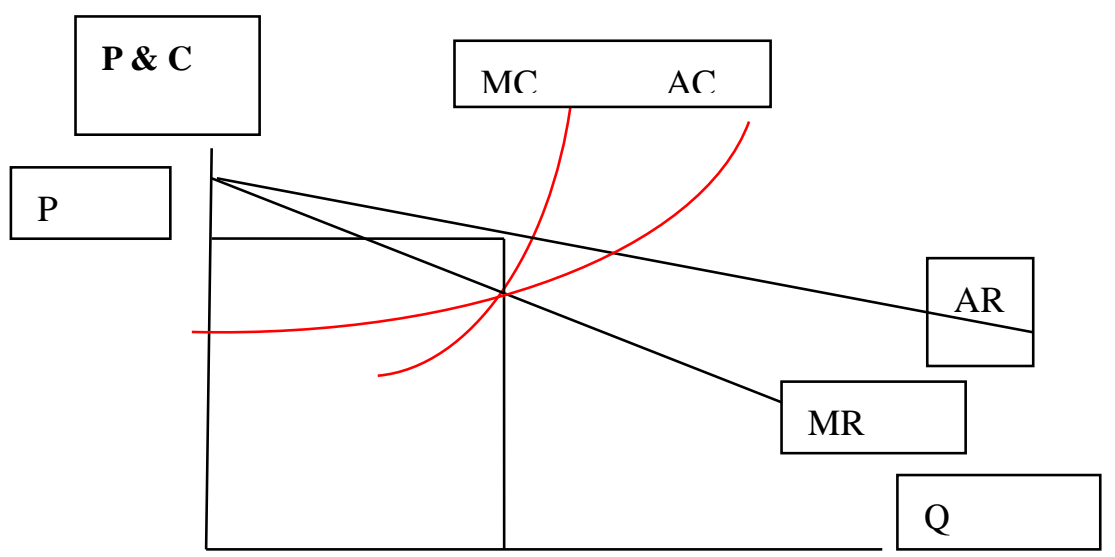

Source: The researcher

(B) Production for export strategy:

It depends on gradual application of open markets strategy to support the export orientation of local infant industries in LDCs.

The strategy depends on:

a) Encouraging export-oriented industries by ensuring the availability of local raw materials.

b) Supporting the local industries through, finance, policies and tax exemption.

c) Encouraging competition through the open door policy.

d) Regulating the exchange rate transactions to promote exports sector.

e) Encourage the participation of foreign capital to provide technology and marketing outlets.

Merits of export-oriented strategy:

a) Widens the size of local markets (internally and externally) and reduces production costs by economizing the scale of production.

b) Achieves greater value added by taking advantage of the comparative advantage, which characterized the export-oriented industries.(cheap inputs)

c) Increases production efficiency by opening local markets and exposing domestic production to foreign competition.

d) less complicated and inexpensive from the procedures point of view.

(D) Productive Art Strategy:

This strategy focused on the procedure of mixing ratio of elements of production. Example (K, L)

The determinants of the Production Art Strategy:

1-types and nature of industries:

The heavy industries are capital-intensive while light industries are labor-intensive. In the figure below we see that the industry (A) the production possibility curve (PPC) is leaning toward capital axis (K) (Capital-intensive industry). On the other hand, industry (B), the production possibility curve (PPC) is leaning toward labor axis (L) (labor-intensive industry). 


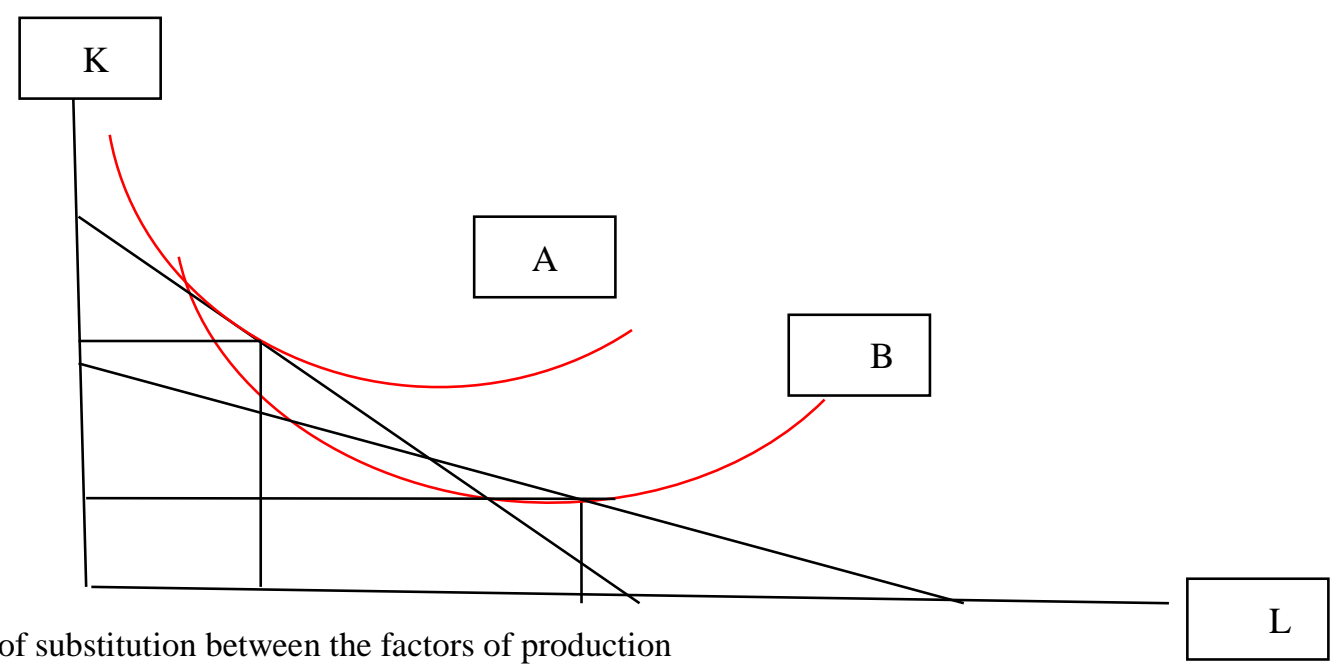

2-The degree of substitution between the factors of production

This degree measured with elasticity of substitution between factors of production
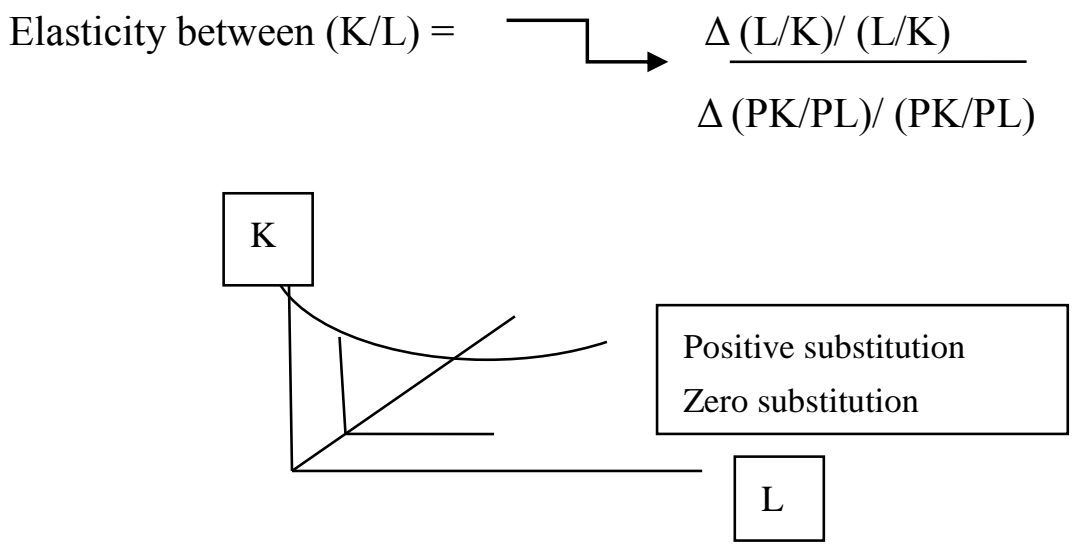

(E) Industry Structure Strategy :

It depends on structural formula of the productive units within certain industry.In addition, the factors that affect it .Usually the industrial structure consist of the level of industrial concentration and products differentiation and vertical and horizontal integration between industries. All these points affect the behavior of industries i.e. its policies on its market share, price, and information.

Determinant factors of this strategy:

- A suitable structure that offers competition between firms i.e. no monopoly.\& at the same time achieve the efficiency of productivity.

- Suitable structure that offer efficient distribution of returns of factors of production within the all units of the industry

All these determinants should be within the production efficiency and the size of the market.

[A] Industrial concentration:

Generally, the concentration ratio is measured by this formula: $\frac{\sum \text { of the big production share of some firms }}{\text { Total production of the industry }}$

When the ratio equals one or becomes near to one, the industry will characterized by high concentration (monopoly). On the other hand, when the ratio is near to zero, the industry behavior is characterized by free competition.

Also in the L. Index ( $\mathrm{P}-\mathrm{MC} / \mathrm{P})$, when the Index equals zero i.e. $\mathrm{P}=\mathrm{MC}$ this reflect perfect competition situation i.e. no concentration.

*Lorenz Curve: 


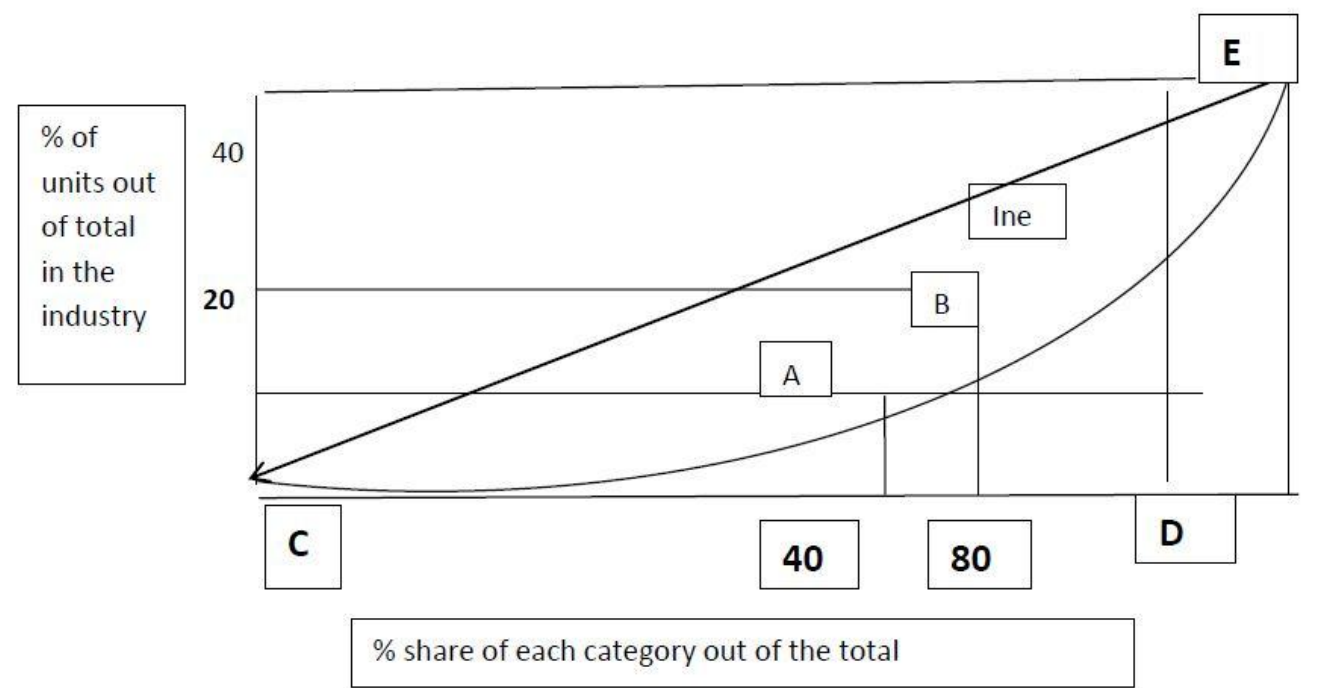

At point (A) on Lorenz, curve in the above figure, $20 \%$ of units' control $40 \%$ of the size of the industry

At (B) $40 \%$ control $80 \%$.so this curve reflects inequalities.Also by using *Gianni Coefficient $(\mathrm{G}$.C) $=$ Area of inequality /area CED. When the value of G.C tends to be zero, this suggests that inequality is diminishing (less concentration), and when the value of G.C tends to be one, this indicates more inequality (i.e. more concentration).

*Hirschman -Herfindahl Index:

$$
\mathrm{n}=\sum\left(\mathrm{k}_{\mathrm{u}} / \mathrm{k}\right)^{2}
$$

$\mathrm{n}=$ total number of firms in the industry

$$
\mathrm{k}_{\mathrm{u}}=\text { size of firm } \mathrm{u} \text {. }
$$

$\mathrm{k}=$ total size of firms in the industry. (Consider the below explanatory table)

\begin{tabular}{lllll}
\hline \multirow{2}{*}{ No of firms } & \multicolumn{2}{c}{ INDUSTRY (A) } & \multicolumn{2}{c}{ INDUSTRY (B) } \\
& Relative share(RS) & Squared (RS) & Relative share(RS) & $\begin{array}{l}\text { Squared } \\
\text { (RS) }\end{array}$ \\
\hline 1 & 0.50 & 0.25 & 0.80 & 0.64 \\
2 & 0.40 & 0.16 & 0.10 & 0.01 \\
3 & 0.10 & 0.01 & 0.10 & 0.01 \\
TOTAL & & 0.42 & & 0.66 \\
\hline
\end{tabular}

From the above table, the concentration ratio for firm $(1)$ and $(2)=0.9(50+.40=0.90)$ and $(0.80+0.10=0.90)$ for the two industries $(A)$ and(B) . But with Herfindahl Index $=0.25+0.16=0.41$ industry $(A)$ and $=0.64+0.01=0.65$ industry (B) . So this index consider weight of the relative shares, so by concentration ratio the share of the less size firm out of the big sized firm in industry $(\mathrm{A})=0.1 / 0.50=0.20$. But by Herfindahl Index the less sized firm contribute with 0.04 i.e. $(0.01 / 0.25)$. The value of Herfindahl Index tends to one which reflect condition of monopoly. When the value tends to zero this, reflect competition condition (many firms).

Why measure industrial concentration?

It is necessary to measure industrial concentration to assess the following:-

a) degree of competition

b) the barriers facing the industries

c) the level of importation 
d) the structural ownership.

e) the relation between the degree of concentration and employment.

The factors that affect industrial concentration:

The following factors are influential in determining industrial concentration:

a) The size of industrial market: - through number and size of firms

b) Merging:-if the merging process is vertical, (two firms produce integrated commodities, one firm produces cars and the other produces the spare parts), the concentration will be weak because the two commodities do not resemble absolute substitutes.

On the other hand, horizontal merging (firms producing substitute commodities) reduces concentration by decreasing the number of firms.

[B]Industry entry barriers:

This constitutes a basic dimension of industry structure, representing hindrances against firms' entry to the industry.

Types of barriers:

1-Economies of the scale:- Reflects the huge size of production, which achieves the minimum efficiency of the scale. Nevertheless, any reduction of level of production increase (AC).

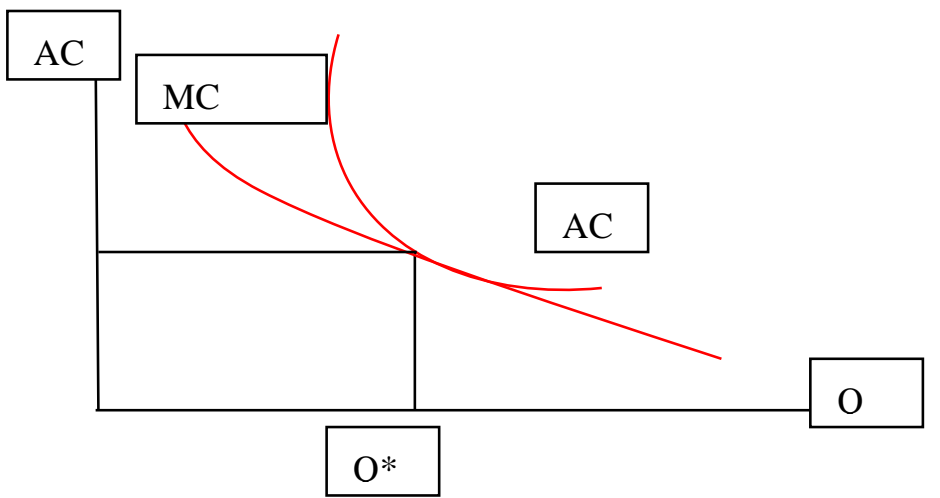

At $\left(Q^{*}\right)$ the firm achieves the minimum efficient scale:

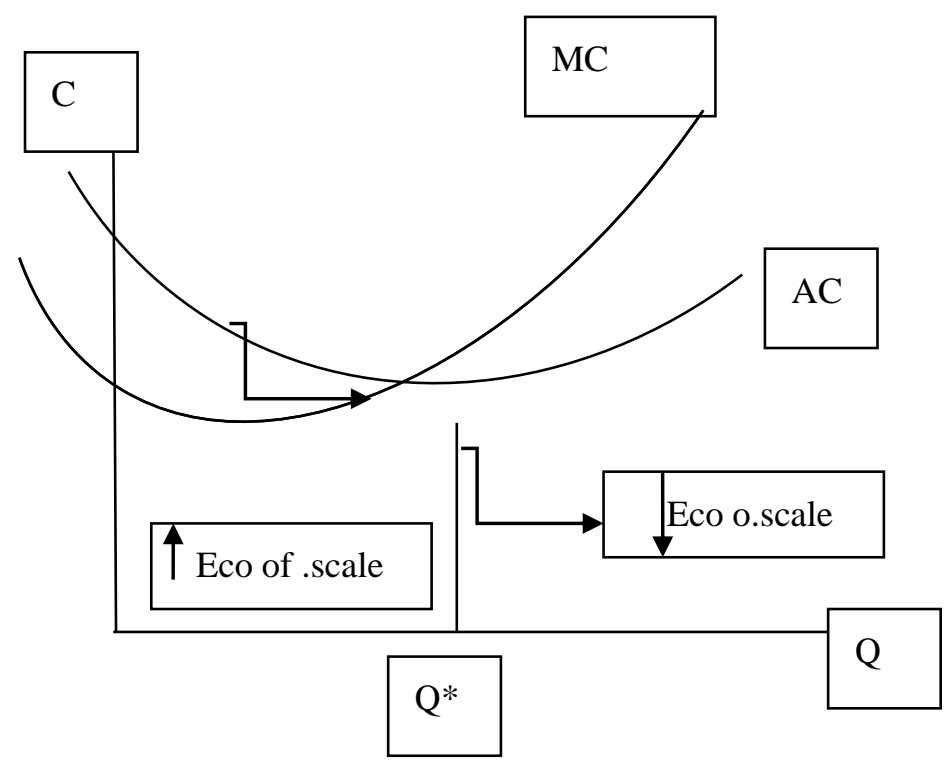

[C] Absolute cost advantages

Denotes the high (AC) for newly established firms in comparison to other firms in the industry: 


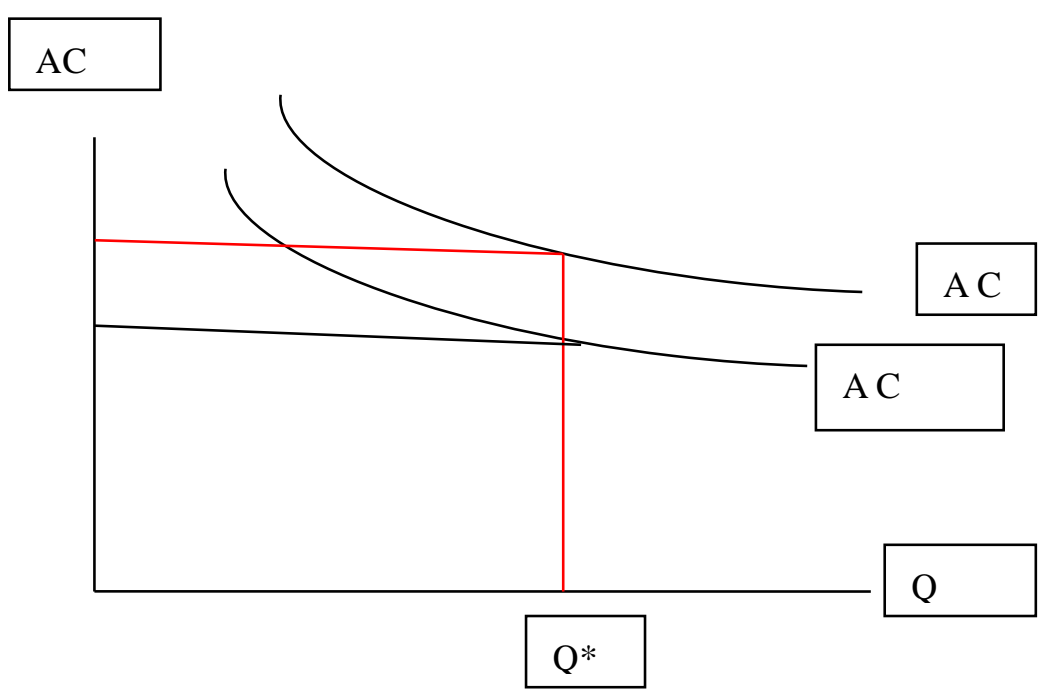

The factors that influence production cost and consequently determine the entry of new firms can be listed as follows:

- Creativity certificates owned by the firms in the industry, which represent a huge cost in the face of the new industry firms.

- ownership of rare raw materials by the firms in the industry, which facilitate adoption of price strategy (price-transfer/or subsidizing) that hinders new industry firms entry.

- Availability of financial sources at low costs for the firms in the industry.

- Availability of hard currency for the firms in the industry.

[D] The range of the vertical integration:

Forward and backward integration:

Example of vertical backward integration:-leather products firm own leather raw material firm. In this case, the firm benefited from market extension through increasing the demand on its products.

Example of vertical forward integration is like a firm producing plastic own a firm producing plastic tools. In this case, the firm achieves absolute cost advantage by obtaining raw material from other firms integrated with it.

[D] The degree of customs protection:

Customs protection can be achieved by:
a) customs tariff
b) importations licenses
c) determination of imports quantities

Within the context of the above literature review, the study attempts to check the economic contribution of Sudanese transformational industries

(B)The economic role of transformational industry in Sudan

\section{The structure of Sudanese transformational industry (TI)}

\subsection{Composition of Sudanese transformational industry}

In this respect, the study will follow the Statistical description analysis of Sudanese Transformation Industry (TI), to check the its concentration (numbers of each type in the industry) and its localization. 
Table No (1) \%Average and Number of (TI) industries according to type (during the period of study):

\begin{tabular}{clcc}
\hline NO & \multicolumn{1}{c}{ Types of industries } & NO & \% \\
\hline 1 & Food and beverages & 16974 & $70 \%$ \\
2 & Textiles & 238 & $1 \%$ \\
3 & Blue hide and Leather industry & 461 & $2 \%$ \\
4 & Wood and papers industries & 917 & $4 \%$ \\
5 & Chemical and oil industries & 343 & $2 \%$ \\
6 & Extraction of non mineral industry & 1541 & $6 \%$ \\
7 & Mineral industries & 2812 & $11 \%$ \\
8 & Stationary industries & 17 & $1 \%$ \\
9 & Electrical equipment & 12 & \\
10 & Radio and TV industries & 51 & 2 \\
11 & Medical industries & 53 & $1 \%$ \\
12 & Transport and equipment industries & 521 & 172 \\
13 & Furniture industry & 24114 & $100 \%$ \\
15 & Others & & $2 \%$ \\
\hline
\end{tabular}

Industrial survey -Ministry of Industry- March $2005+$ recent reports

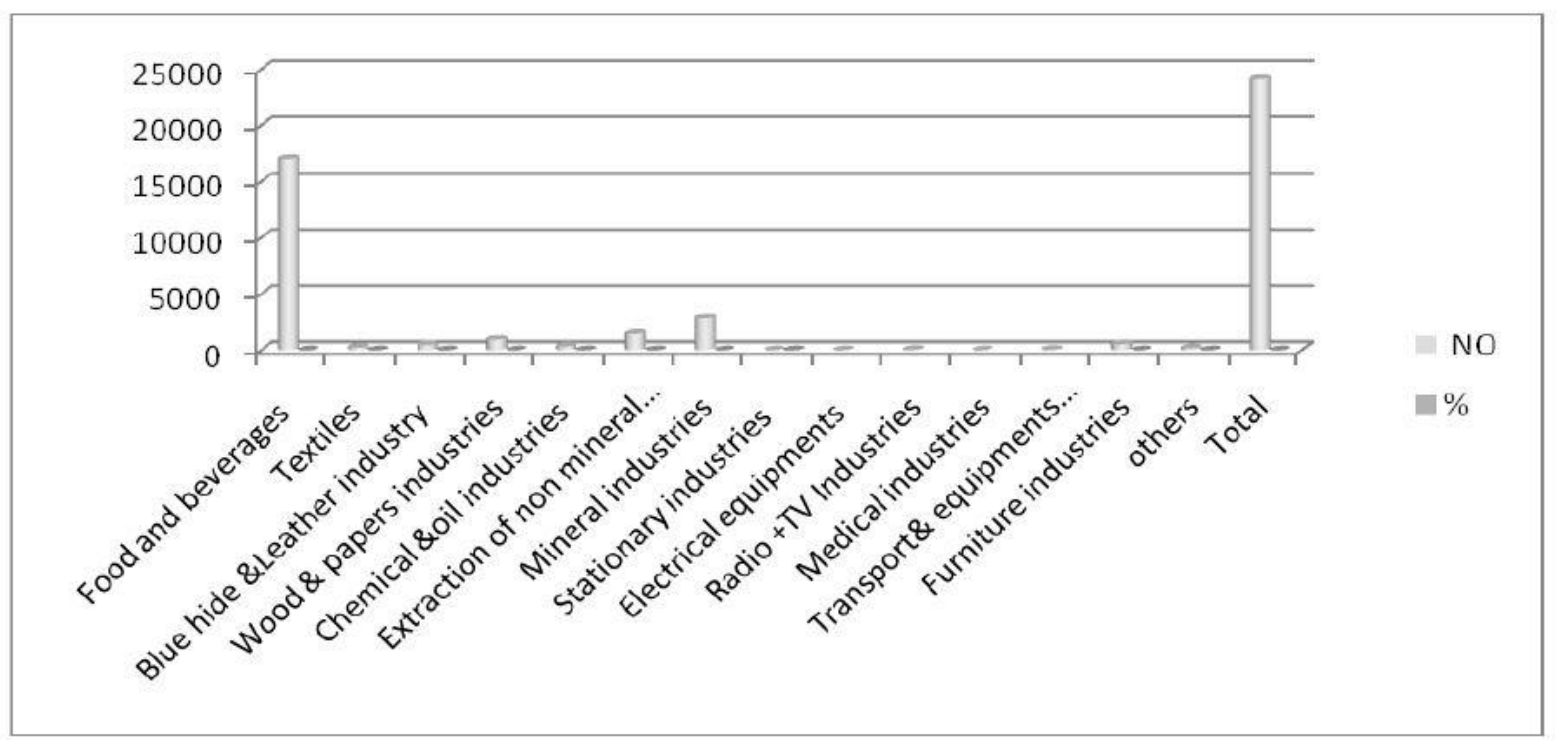

From the above table No (1) we see that $70 \%$ of the total numbers of (TI) firms are concentrated in food and beverages industries, this is a reflection of the agriculturally oriented policy of (TI) in Sudan. But at the same time the other important agro-base industries like textiles, blue hide and leather , and wood industries share out of the total number is around $7 \%$ only .

Table NO (2)

\begin{tabular}{lcc}
\hline \multicolumn{1}{c}{ INDUSTRY (A) } & Share relatives (S.R) & S.R Squared \\
\hline 1. Food and beverages & 0.70 & 0.49 \\
2.minerals +non mineral & 0.17 & 0.0289 \\
3.others & 0.13 & 0.0169 \\
\hline
\end{tabular}

Recent reports of ministry of industry

From the above table $\mathrm{No}(2)$ The concentration ratio of $(1)+(2)$ firms $=0.70+0.17=0.87$, for the two types of industries (1)(Food and beverages) and (2)(minerals + non minerals). But by using Herfindahl Index $=0.49+0.0289=0.5189$. So the two methods of calculations reflect a condition of monopoly towards both types of industries .Also for the two Indexes the share of less size industries (3) out of the big share industries in ( TI) sector $=$ $0.13 / 0.70=0.186$. However, by Herfindahl Index the less sized firm contributes $(0.0169 / 0.49)=0.035$ this value also confirms the existence of concentration in the above said industries i.e. the condition of monopoly. 
Table No (3) \% average distribution of transformational industries according to the States

\begin{tabular}{|c|c|c|c|c|c|c|c|c|c|c|c|c|c|c|c|}
\hline NOR & NILE & RED & KASS & GAD & KHA & GEZ & SENN & W.NI & B.NI & N.KOR & WKO & SKO & $\mathrm{NDA}$ & WDA & SDAR \\
\hline 3.6 & 5 & 1.8 & 3.4 & 5.7 & 20 & 13.5 & 5.1 & 6.1 & 2 & 4.8 & 2 & 3.5 & 5 & 1.5 & 17 \\
\hline
\end{tabular}

Industrial survey -Ministry of Industry- March 2005

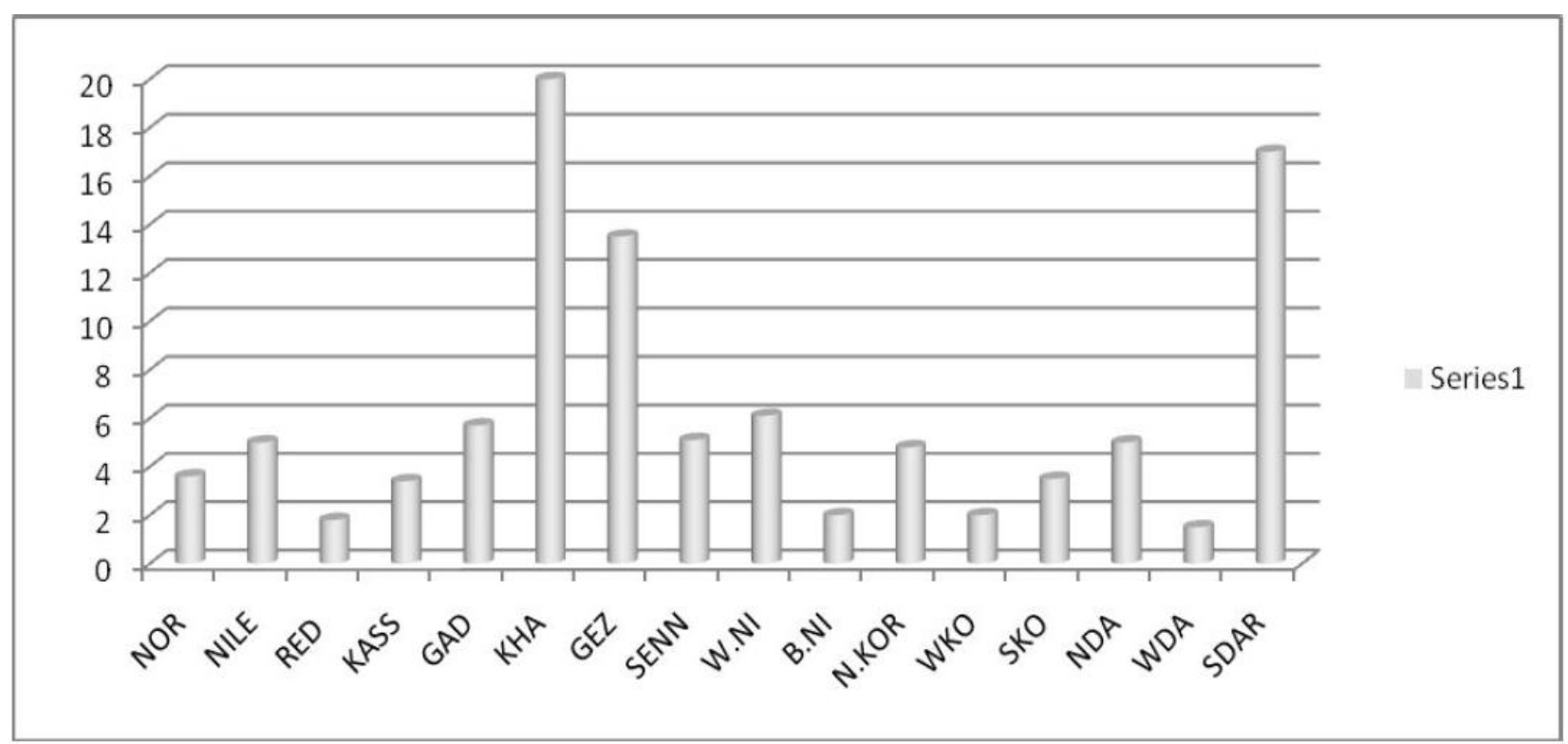

This table (NO 3) reflects misdistribution of the transformational industrial firms within the country i.e. over $50 \%$ of the firms are localized in three states (Khartoum, South Darfur and Gezira). Some economists, however, believe that (firms of similar industrial activities should be concentrated in certain areas. This is expected to make skilled workers and specialised suppliers easier to find. In addition, valuable knowledge can be shared among producers.) 8 , Nevertheless, in the case of Sudan (TI), localization did not consider the orientation of clustering of activities hence negatively affected the socio-economic development at macro level.

Table NO (4) \% contribution of large scale and small scale firms of the(TI) in the employment

\begin{tabular}{cc}
\hline Large scale industries (above 100 workers) & Medium and Small scale industries(below 100 workers) \\
\hline $60 \%$ & $40 \%$ \\
\hline
\end{tabular}

Ministry of industry reports 2012

\footnotetext{
8 Guido Buenstorf and Steven Klepper-INDUSTRY CLUSTERS: THE IMPORTANCE OF 'SPIN-OFF ENTREPRENEURS'R.E.S-April 2009
} 


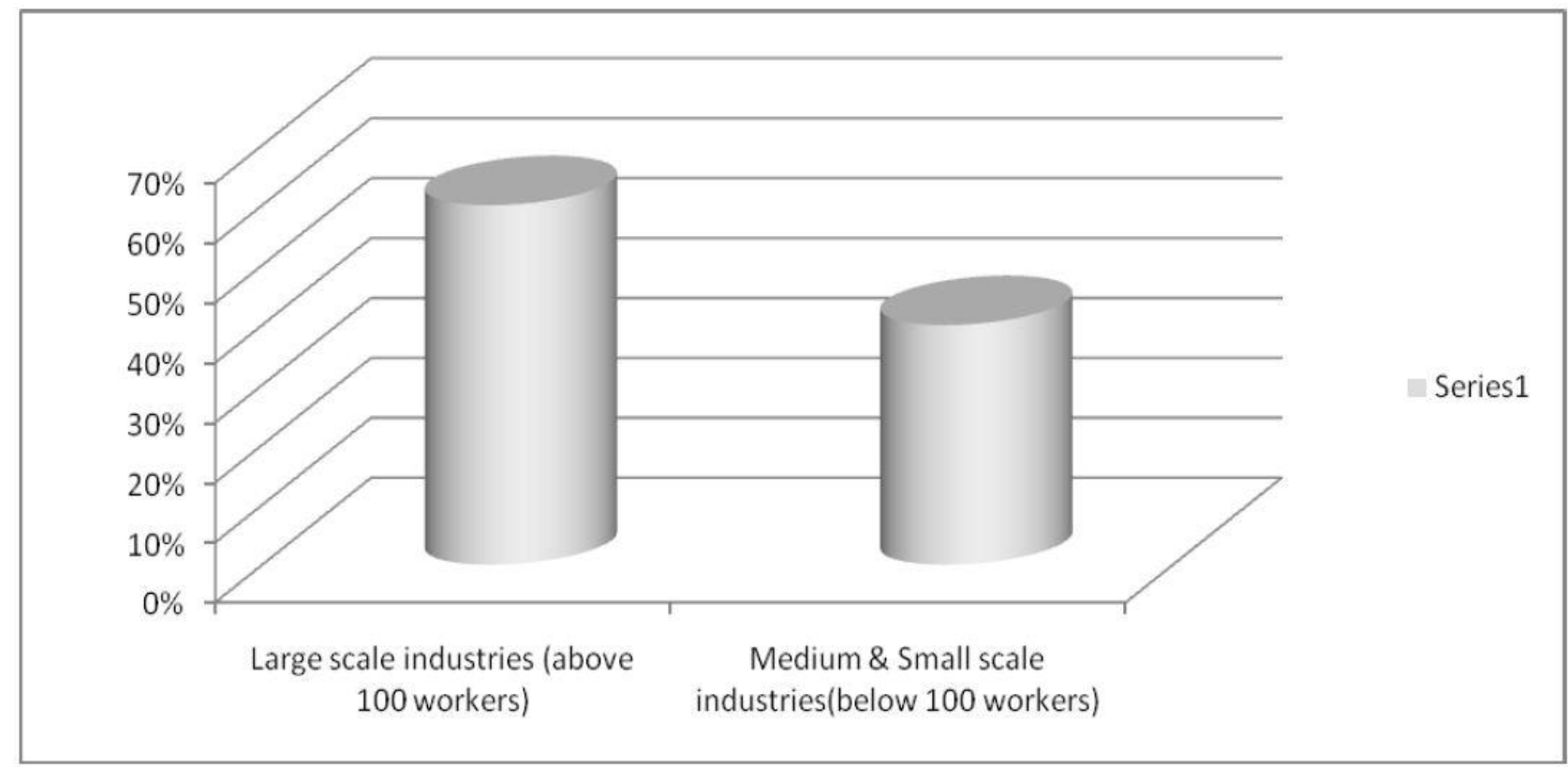

With reference to the above table $\mathrm{NO}(4)$, the Large scale industries contributed with $60 \%$ in the employment while the medium and small -scale industries contributed with $40 \%$,although the number of small and medium scale industries constitute $98.9 \%$ of total number of (TI)in Sudan. This result in my view is related to the structure of employment (size +type) in such firms that depends on owners' decision. Therefore, the medium and small -scale industries in (TI) sector not encourage employment; therefore not contribute in mitigation of unemployment rate.

Table NO (5). \% average classification of transformational industry (TI) according to the NO of workers (Size classification according to the NO of workers)

\begin{tabular}{|c|c|c|c|c|}
\hline 10 & -24 & $25-49$ & $50-99$ & Above 100 \\
\hline 93.1 & 3.8 & 1.4 & 0.6 & 1.1 \\
\hline
\end{tabular}

Industrial report- 2012

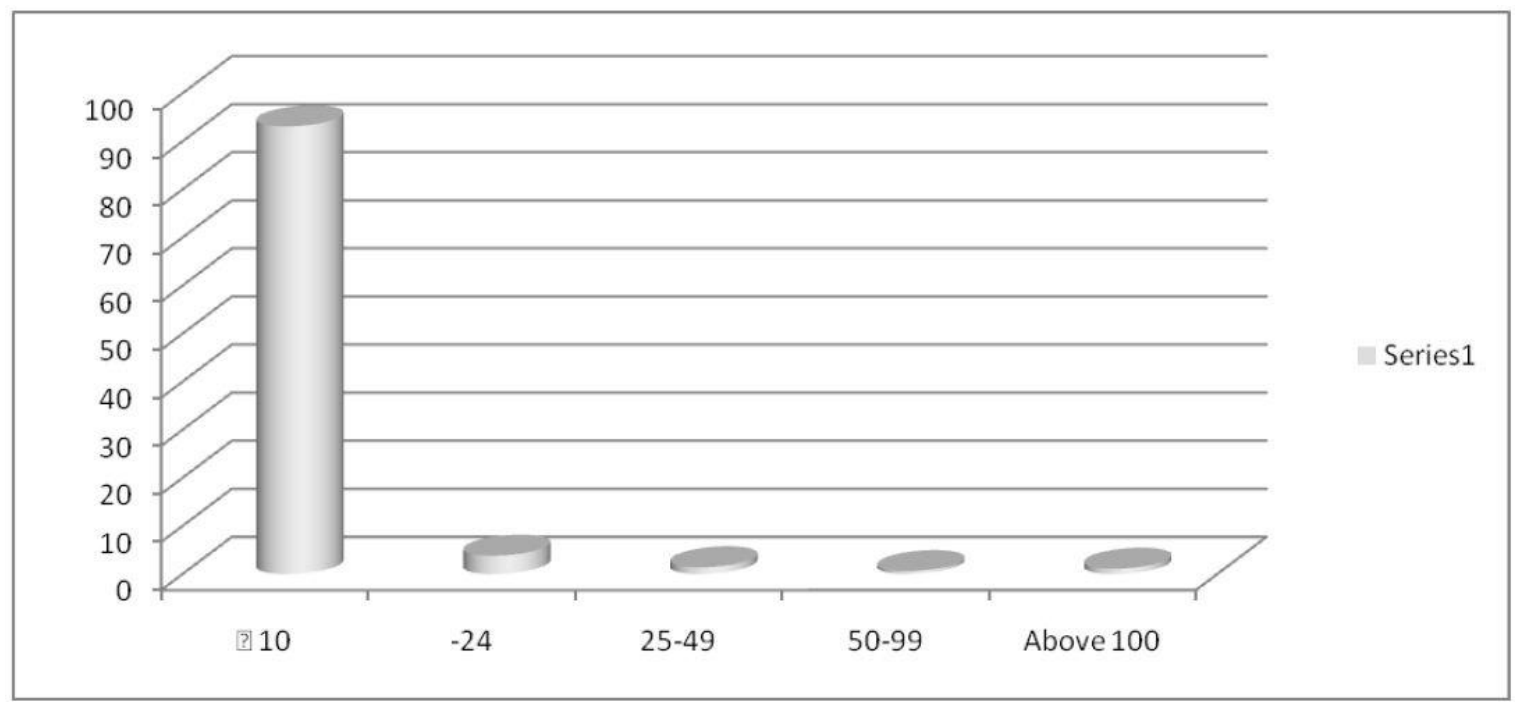

The above table (NO 5) expresses that (93.1\%) of the (TI) firms are small size firms

This resulted in the marginal share of (TI) in the economy, because small -scale firms has no sound effect on value added. 
Table No(6) Sector component of transformational industry

\begin{tabular}{cc}
\hline Types of industries & $\%$ \\
\hline Food and beverages & 70 \\
Minerals and related products industries & 12 \\
Others & 18 \\
Total & 100 \\
\hline
\end{tabular}

Industrial survey -Ministry of Industry- + 2012 reports

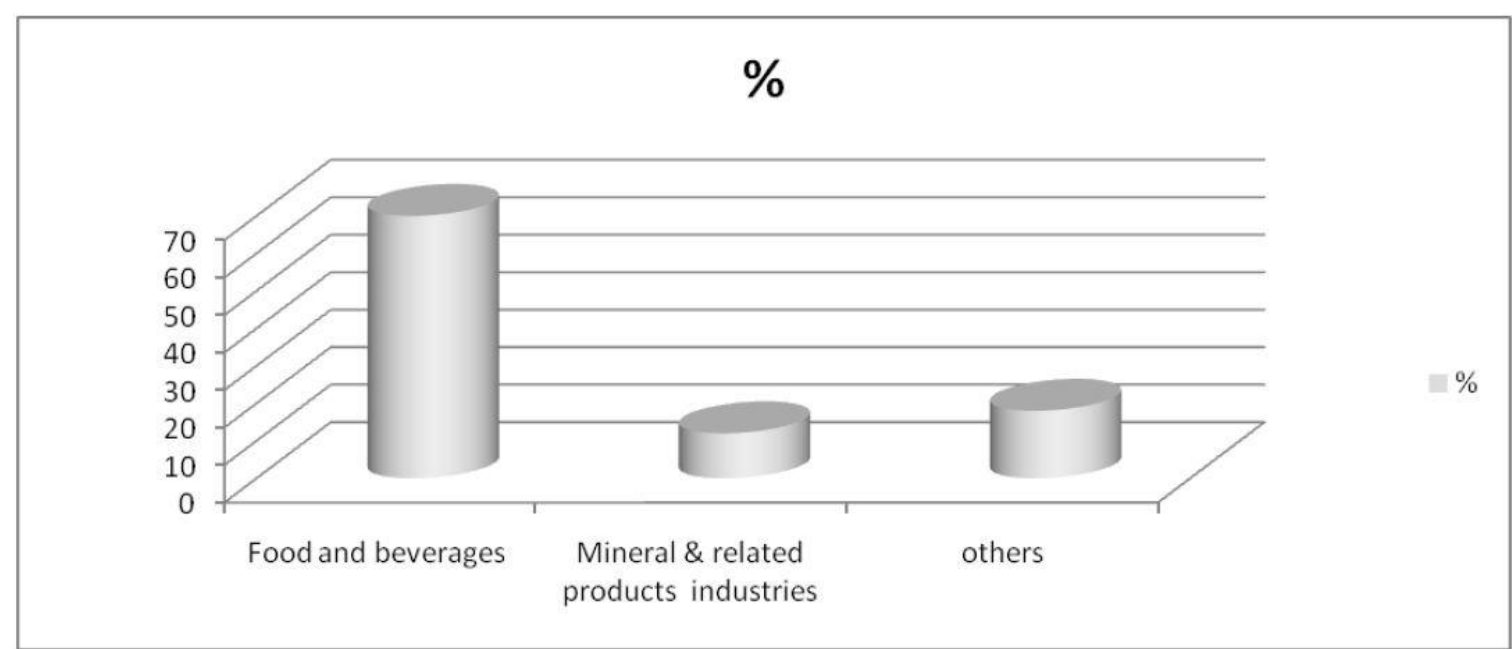

This table (No 6) reflects that $70 \%$ of the component of the transformational industry (TI) devoted to the food and beverages, and this show high dependency of (TI) on agricultural sector and there is weak concern with other real production sectors.

In addition, the table explains that the sector component of the (TI) is very less diversified because (82\%) out of all firms in (TI) concentrated in only two industries (food and beverages + Mineral and related products).

Result shows the weak contribution and performance of the majority of (TI) industries.

Table No (7)\% average contribution of (TI) in value added of (TI) according to the firms size

Large scale industries (above 100 workers)

Medium and Small scale industries(below 100 workers)

$68 \% \quad 32 \%$

\section{Ministry of industry reports 2012}

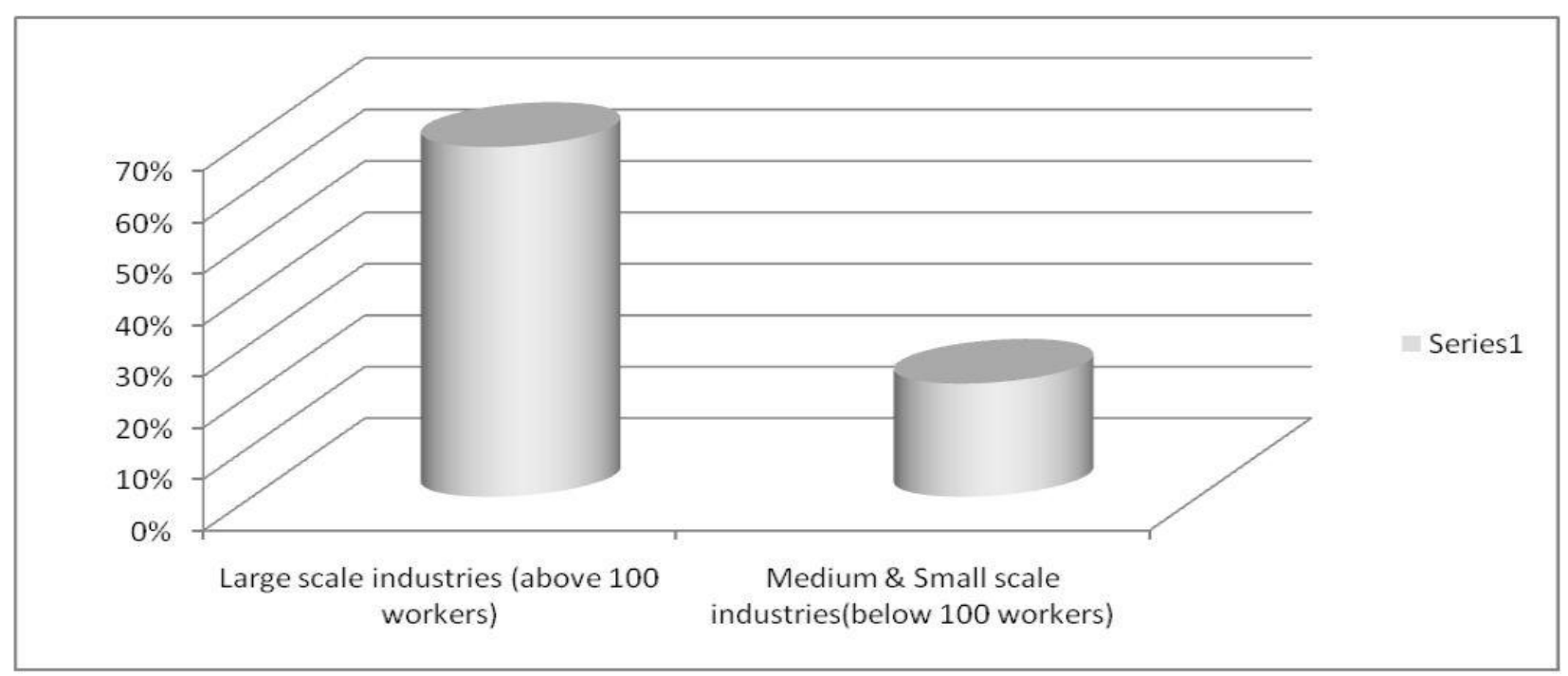

The table(NO 7) shows that the large-scale industries (LSI) are highly economic efficient than the small-scale industries, 
accordingly the share of (LSI) in value of (TI) represents $68 \%$, and all medium and small -scale industries contribute with only $32 \%$.

So the above analysis confirms the first hypothesis that:

There is a significant relation between Sudanese (TI) structure and its economic performance.

\section{The Economic Contribution of Sudanese (TI)}

5.1 (TI) Share In industrial value added and in gross domestic product (GDP)

Table NO (8)Average \% share of transformational industrial sector`s value added in GDP

\begin{tabular}{llc}
\hline NO & \multicolumn{1}{c}{ Types of industries } & $\%$ \\
\hline 1 & Food and beverages & 6.5 \\
2 & Textiles & 0.2 \\
3 & Blue hide and leather industry & 0.1 \\
4 & Wood and papers and publication industries & 0.3 \\
5 & Chemical industries & 1.5 \\
6 & Extraction of non-minerals industry & 0.3 \\
7 & Mineral industries & 0.2 \\
8 & Stationary industries & 0.01 \\
9 & Electrical equipment & 0.03 \\
10 & Radio and TV industries & 0.004 \\
11 & Medical industries & 0.001 \\
12 & Transport and equipment industries & 0.3 \\
13 & Furniture industry & 0.02 \\
15 & Others & 1.04 \\
16 & Total & 10.505 \\
\hline
\end{tabular}

Industrial survey -Ministry of Industry- March $2005+$ other reports (2006/2014)

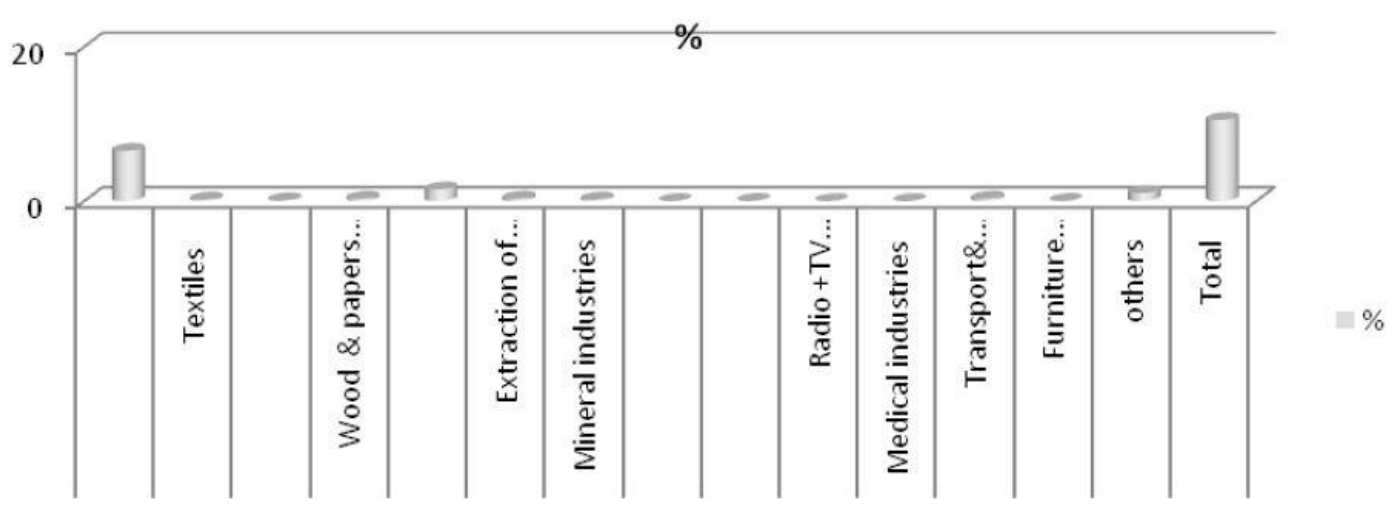

From the above table (No 8) the total value added of (TI) in GDP is minimal, indicating that the Sudanese (TI) firms have not maximized the value of output. This result confirms the previous analysis of Table (4). In my view, the food and beverages industries were not efficient in maximizing the value of products compared to other industries. 
Table No (9) Average \% share of Industrial transformation sector in value added of Transformation industry

\begin{tabular}{llc}
\hline NO & \multicolumn{1}{c}{ Types of industries } & $\%$ \\
\hline 1 & Food and beverages & 65 \\
2 & Textiles & 3 \\
3 & Blue hide and leather industry & 1.5 \\
4 & Wood and papers and publication industries & 3.3 \\
5 & Chemical +oil refinery industries & 18 \\
6 & Extraction of non-minerals industry & 2.5 \\
7 & Mineral and related products industries & 2.5 \\
8 & Stationary industries & 0.2 \\
9 & Electrical equipment & 0.3 \\
10 & Radio and TV industries & 0.1 \\
11 & Medical industries & - \\
12 & Transport and equipment industries & 3 \\
13 & Furniture industry & 0.2 \\
15 & Others & 0.4 \\
16 & Total & 100 \\
\hline
\end{tabular}

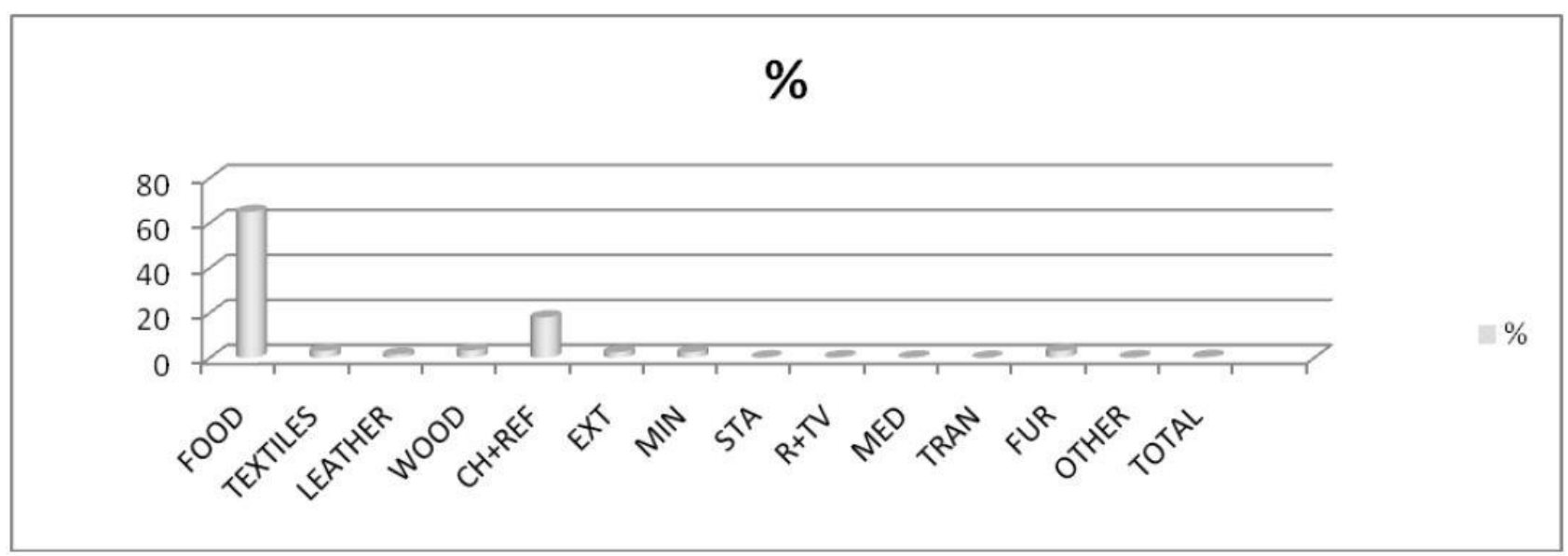

The table (NO9) shows that only two industries (Food and beverages) + (Chemical and oil refinery industries) dominate $(83 \%)$ of the total value added of transformational industry ( TI). This result shows the weak contribution and performance of the majority of (TI) industries.

Table Non (10)Contribution of (TI) IN GDP of certain countries

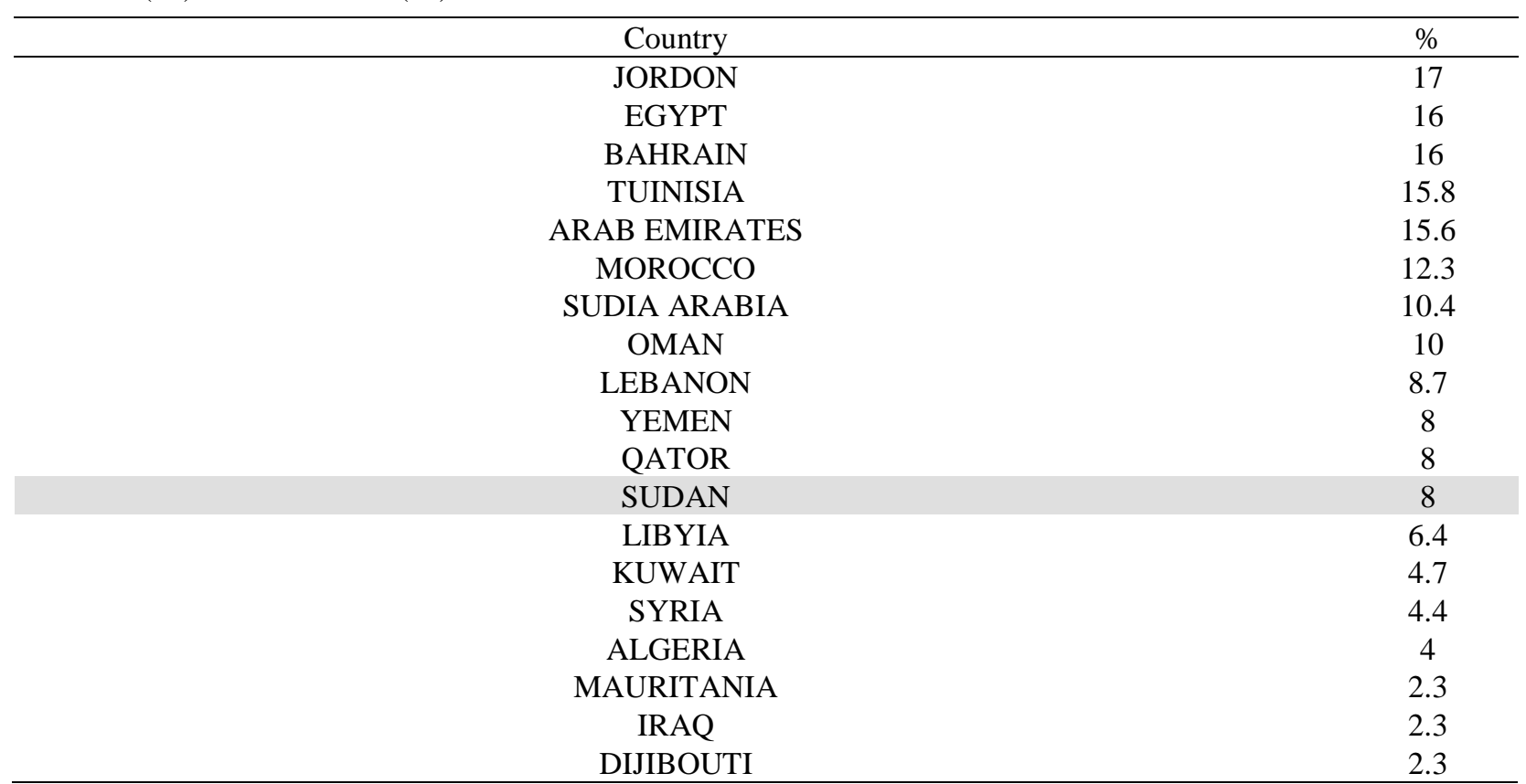




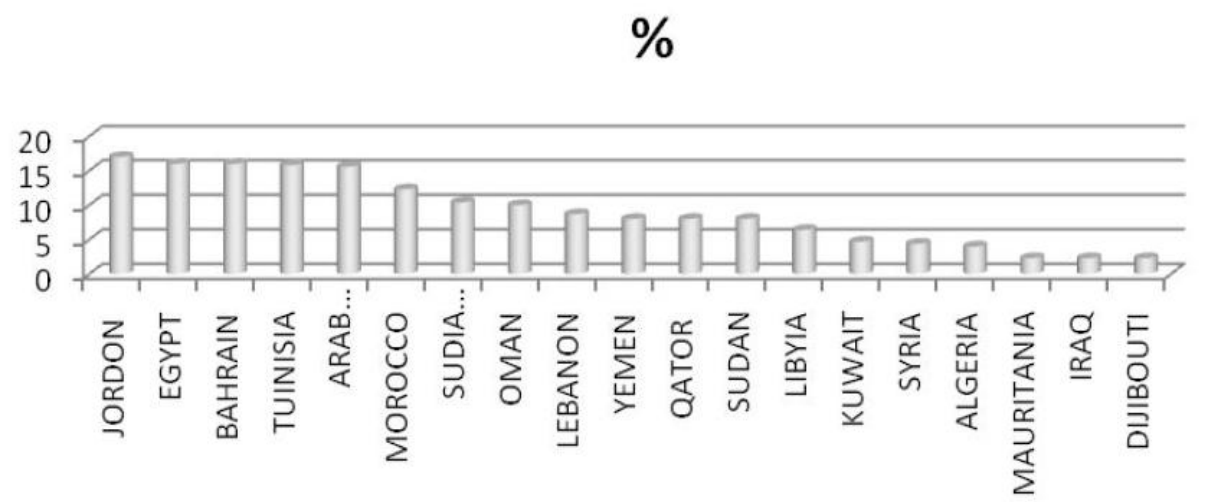

This above data ( Table No 10) which had been collected from UNIDO 2009 REPORT, reflect minor contribution of Sudanese (TI) in GDP compare with other countries in the area, beside the fact that the majority of these countries depend on extraction industries.

Table NO (11)\% share of Manufacturing industry*1 (MI) and Industry*2 in Value Added of GDP

\begin{tabular}{ccc}
\hline \multirow{2}{*}{ YEARS } & $\begin{array}{c}\text { \% share of (MI) IN value added } \\
(\text { GDP) }\end{array}$ & $\begin{array}{c}\text { \% share of (INDUSTRY) IN value } \\
\text { added(GDP) }\end{array}$ \\
\hline 2005 & 6.911866 & 27.69108 \\
2006 & 6.065014 & 27.76336 \\
2007 & 6.170126 & 30.61909 \\
2008 & 5.640008 & 33.41518 \\
2009 & 5.997044 & 24.55898 \\
2010 & 5.935627 & 28.42418 \\
2011 & 6.32600 & 27.35185 \\
2012 & 7.883639 & 22.43357 \\
2013 & 8.096313 & 20.89776 \\
2014 & 8.414659 & 20.37515 \\
Total & 67.44029 & 263.5302 \\
Average\% & 6.744029 & 26.35302 \\
\hline
\end{tabular}

World Bank Sudan Report "Development Indicators"

From the above Table (No 11)

*1 (MI) denotes to transformational industries but concentrate on large-scale production industries, the above WB report reflects the \% average share of Manufacture industries which is about 6.7\% , Where the( TI) reflects the effort of both small and large scale industries (so average \% share of(TI) is about $10.5 \%$ which include both small scale and large scale industries Table No -8 )

*2(INDUSTRY) refers to light and heavy industries (processing and extraction)

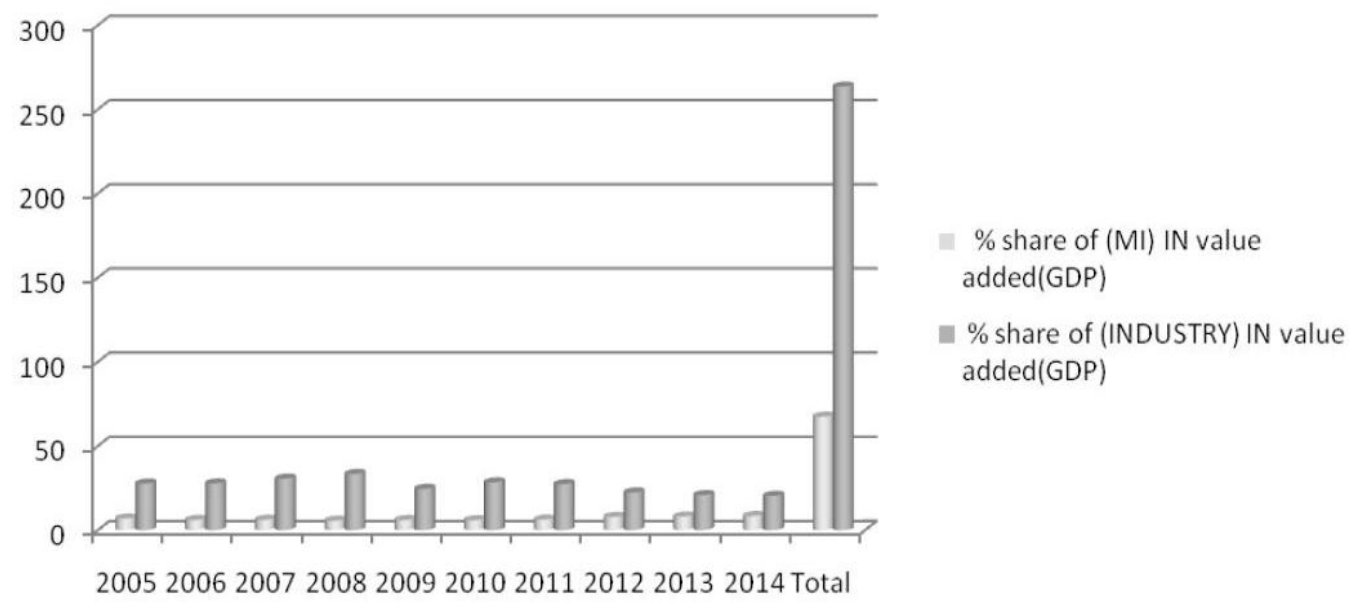

The above analysis reflects that industrial processing (TI) contribution has a weak share in GDP compared to the 
industrial sector in total.

Table NO (12) \% of Value Added for activities of (TI) according to size

\begin{tabular}{lcccc}
\hline \multicolumn{1}{c}{ TI. TYPES } & TINY & SMALL & MEDIUM & LARGE \\
\hline Food and beverages & 21.3 & 1.9 & 12 & 64.8 \\
Textiles & 6.7 & 4.6 & 22.3 & 66.4 \\
Blue hide and leather industry & 9.6 & 44.9 & 4.4 & 41.1 \\
Wood and papers industries & 30.6 & 5.1 & - & - \\
Chemical and oil industries & 1.4 & 0 & 25.8 & 72.8 \\
Extraction of non-minerals industry & 13.5 & 29.8 & 4.4 & 52.3 \\
Mineral extraction and processing industries & 31.1 & 17 & 3 & 48.9 \\
Stationary industries & 0 & 0 & 0 & 0 \\
Electrical equipment & 11.1 & 34.5 & 21.2 & 33.2 \\
Radio +TV Industries & 87.7 & 0 & 12.3 & 0 \\
Medical industries & 0 & 0 & 0 & 0 \\
Transport and equipment industries & 2.7 & 0.7 & 0 & 96.6 \\
Furniture industry & 100 & 0 & 0 & 0 \\
Others & 85.5 & 5.4 & 0 & 9.1 \\
\hline
\end{tabular}

World Bank Sudan Report "Development Indicators"

The large size industries generate the big share of value added specially in food and beverages, Textiles, Chemical and oil industries and Transport and equipment industries. The zero shares reflect non-economic viability of certain firms (cost >return) and usually such industries are supported by the public sector to achieve social benefits.

Above analysis confirms the second hypothesis that:

There is a significant relation between Sudanese (TI) value added and its share in GDP.

3.2. (TI) share in exports and imports -Balance of trade-(BOT)

Table NO (13) \% Share of (TI) exports out of the total exported commodities (2004-2014)

\begin{tabular}{|c|c|c|c|c|c|c|c|c|c|c|c|c|}
\hline ITEMS & 2004 & 2005 & 2006 & 2007 & 2008 & 2009 & 2010 & 2011 & 2012 & 2013 & 2014 & Total \%Average \\
\hline $\begin{array}{l}\text { Food and } \\
\text { beverages }\end{array}$ & - & & 0.2 & 0.04 & - & 0.2 & & 0.03 & & & & 0.043 \\
\hline Textiles & - & - & & 0.12 & 0.31 & - & & & & & & 0.039 \\
\hline $\begin{array}{l}\text { Manufactured } \\
\text { commodities }\end{array}$ & 0.7 & 0.4 & 0.3 & 0.03 & - & & 0.02 & 0.08 & 0.001 & & & 0.139 \\
\hline $\begin{array}{l}\text { Drugs and } \\
\text { chemicals }\end{array}$ & - & - & & - & - & & & 0.20 & & 0.04 & 0.04 & 0.025 \\
\hline Share of (TI) & 0.7 & 0.4 & 0.5 & 0.19 & 0.31 & 0.2 & 0.02 & 0.31 & 0.001 & 0.04 & 0.04 & 0.246 \\
\hline $\begin{array}{l}\text { Share of non } \\
\text { (TI) }\end{array}$ & 99.3 & 99.60 & 99.5 & 99.81 & 99.69 & 99.88 & 99.98 & 99.69 & 99.999 & 99.96 & 99.96 & 99.754 \\
\hline
\end{tabular}

Source: Economic Review -ministry of Finance

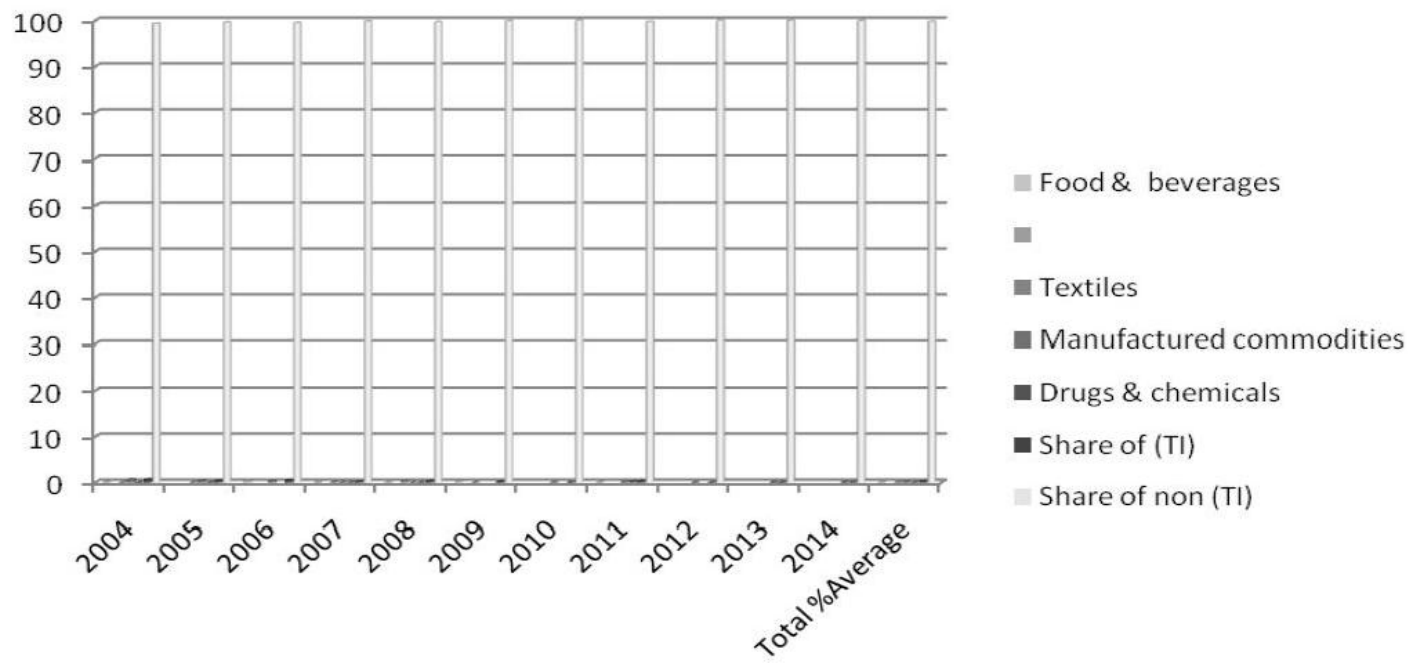




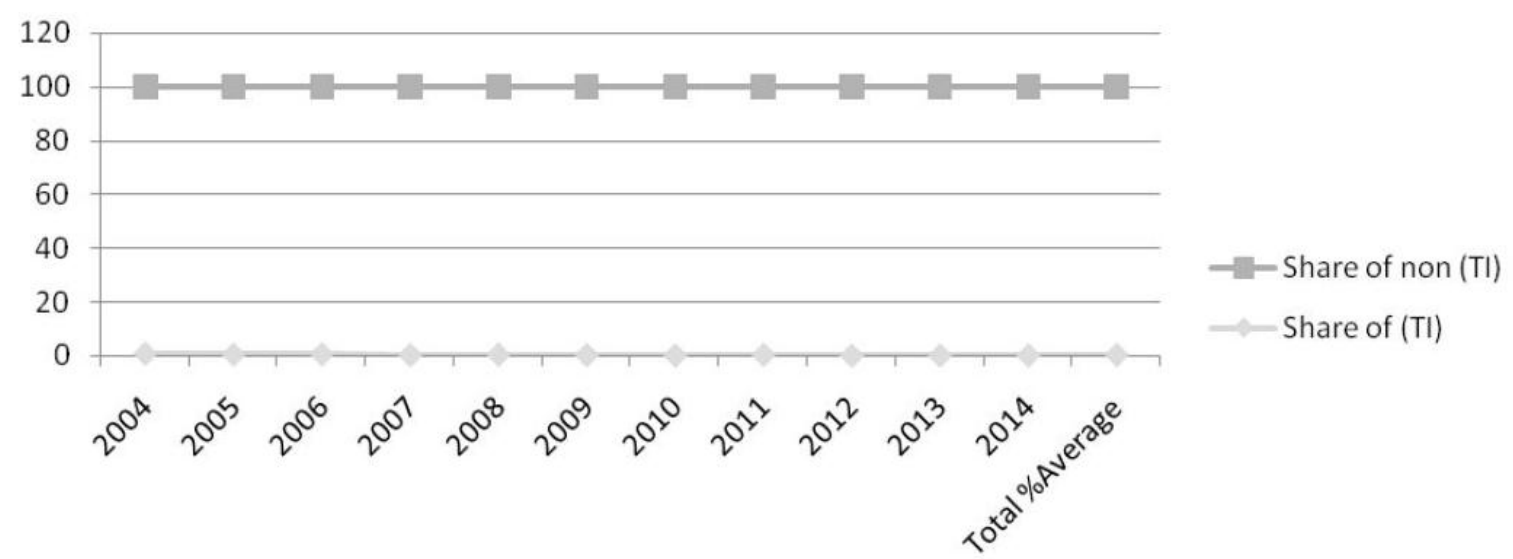

The above diagram and charting obtained from the table reflects zero shares of (TI) products in the total exports of the country.

(14) \% Share of (TI) imports out of the total imported commodities - 2004-2014

\begin{tabular}{ccccccccccccc}
\hline ITEMS & 2004 & 2005 & 2006 & 2007 & 2008 & 2009 & 2010 & 2011 & 2012 & 2013 & 2014 & Total \%Average \\
\hline $\begin{array}{c}\text { Food and } \\
\text { beverages }\end{array}$ & 13.7 & 12.6 & 9.8 & 11 & 14.9 & 18.1 & 24.4 & 20.5 & 22 & 24 & 25 & 17.82 \\
$\begin{array}{c}\text { Textiles } \\
\text { Manufactured }\end{array}$ & 2.5 & 3.5 & 3.7 & 4 & 3.2 & 3.5 & 3.8 & 5.8 & 0.03 & 0.03 & 3.6 & 3.06 \\
$\begin{array}{c}\text { commodities } \\
\text { Drugs and }\end{array}$ & 24.5 & 24.1 & 20.3 & 22 & 20.7 & 25.7 & 20.3 & 18.8 & 0.21 & 0.19 & 1.8 & 14.6 \\
$\begin{array}{c}\text { chemicals } \\
\text { Share of (TI) }\end{array}$ & 48.7 & 7.3 & 6.1 & 6 & 7.3 & 8.9 & 9.6 & 11.2 & 0.08 & 0.05 & 0.06 & 5.87 \\
$\begin{array}{c}\text { Share of non } \\
(\mathrm{TI})\end{array}$ & 51.3 & 52.5 & 60.1 & 57 & 53.9 & 51.4 & 41.9 & 43.7 & 43.32 & 75.92 & 69.54 & 58.65 \\
\hline
\end{tabular}

Source: Economic Review - ministry of Finance

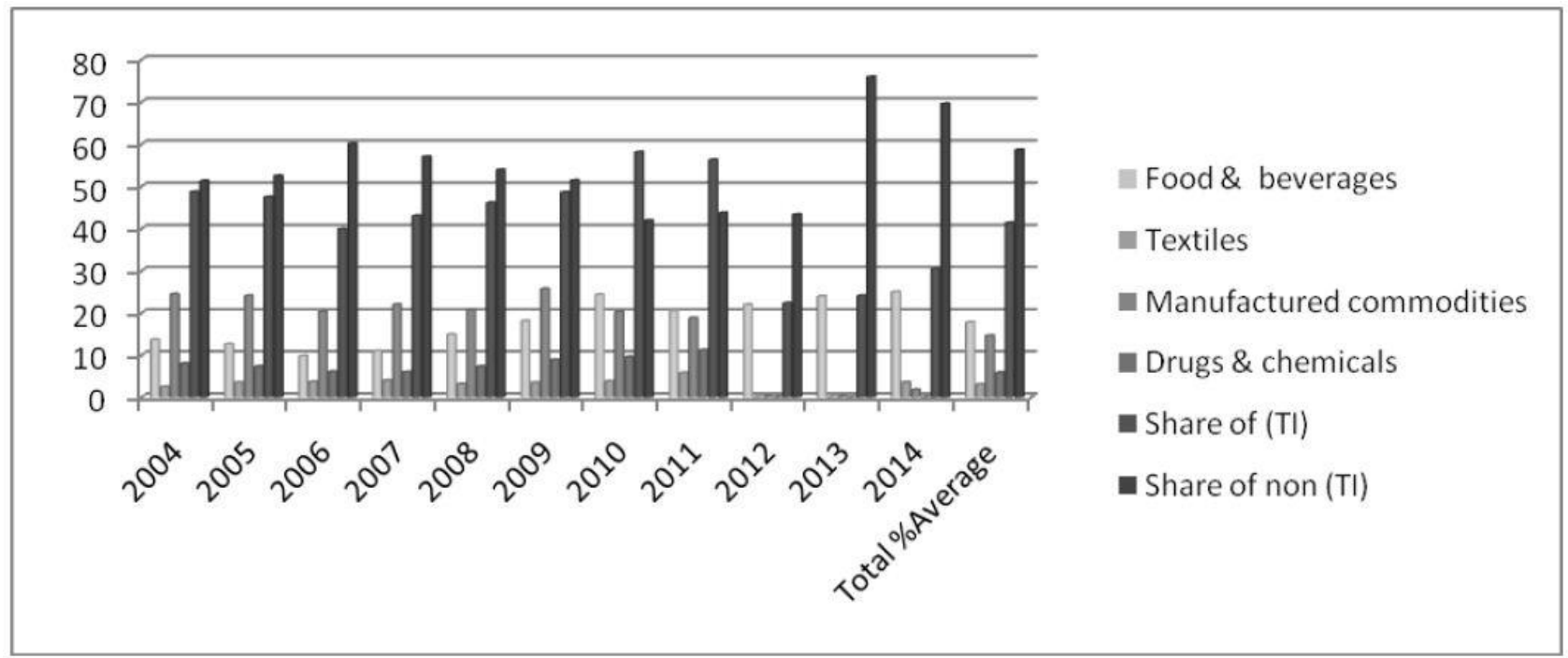

Total \% share of total (TI) products IMPROTS R EALTIVE TO (NON-TI) IMPORTS DURING 2004-2014 


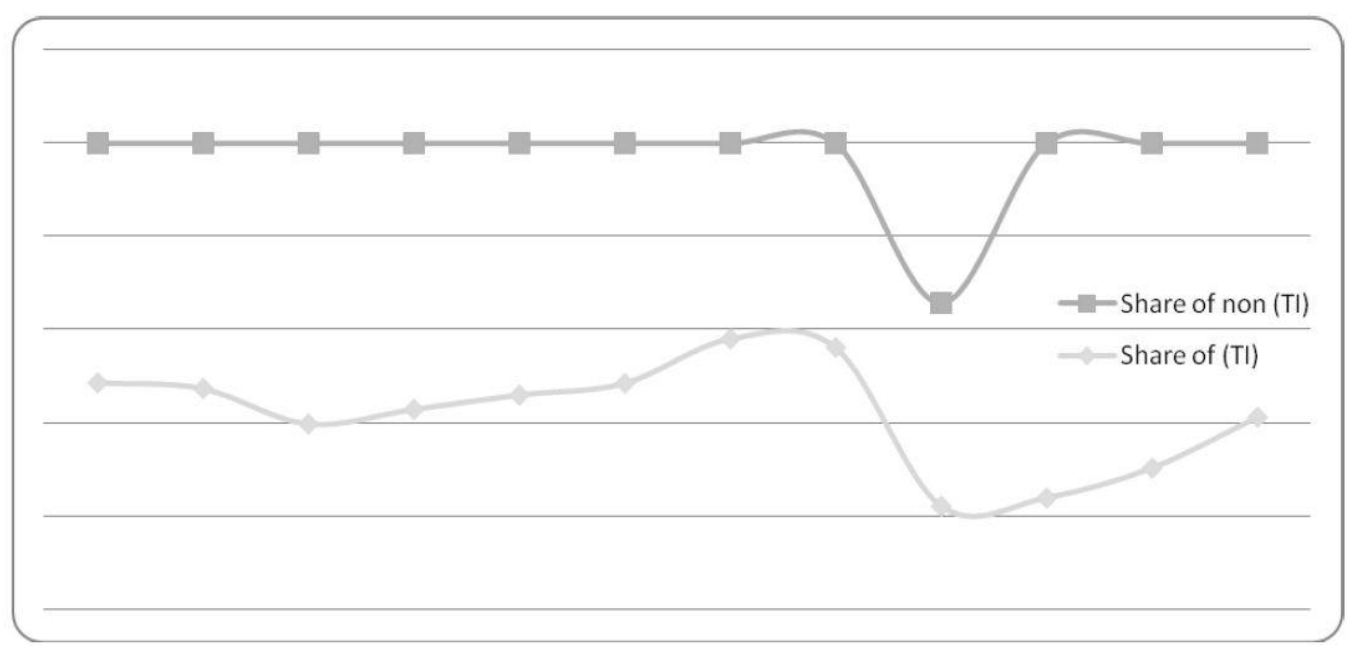

These above diagrams which obtained from table No (14) shows increasing trend of manufactured commodities imported from other countries, this definitely confirm the marginal participation of ( TI) products to meet local demand and at the same time account for high pressures on foreign currency .

$\%$ share of ( TI)and ( non TI) in total imports

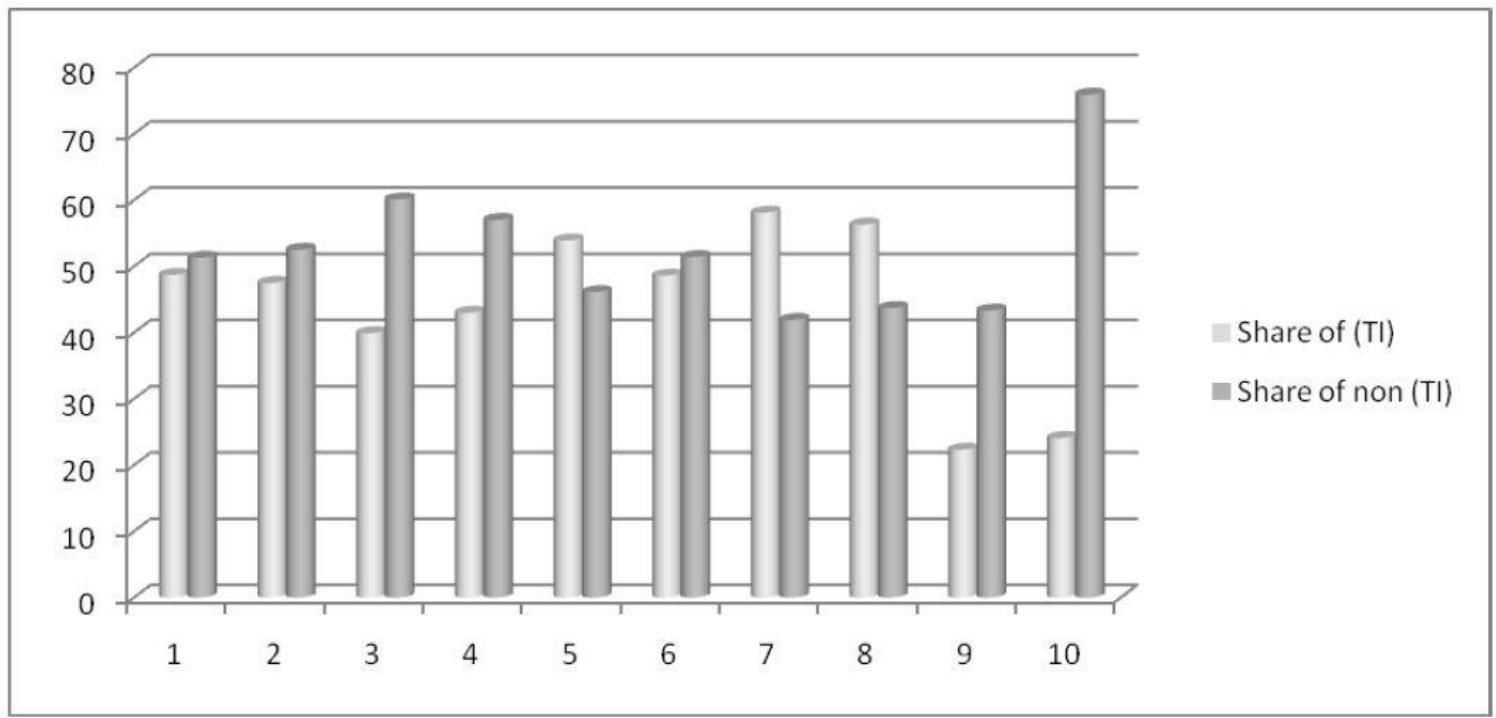

The general trend reflects increasing \% share of (TI) out of the total imports specially in food and beverages, although the food and beverage industry constitute the basic industry in the structure of the country (TI).

Table No (15) Sudan (TI) according to the International index of specialization (IIS)* compare with some countries in the region.

\begin{tabular}{|c|c|}
\hline Product & Country and (IIS) Value \\
\hline Fertilizers & Jordon 92-Tunisia42-Bahraian 23 -Morocco 17 -Sudan 0 \\
\hline Textiles & Tunisia 67- Jordon52- Morocco $27 \quad$-Sudan 0 \\
\hline Chemicals & Morocco 31-Jordon29- Tunisia22- Sudan 0 \\
\hline Salt & Jordon 38-Morocco24-Sudan 0- \\
\hline Fishery & Mauritania 64-Yemen 8-Sudan 0 \\
\hline Aluminum & Bahrain 95 -Sudan 0 \\
\hline Raw Iron products & Mauritania 316 -Sudan 0 \\
\hline Leather & Djibouti 19-Sudan 0 \\
\hline
\end{tabular}

International Trade Center, UNCTAD/WTO 2009:

- $\quad($ IIS $)=($ difference between the balance of payment of certain product and the total balance of payment) $\mathrm{X}$ (trade value of the product/total trade value ) 
- Whenever this index is positive and high this indicates that, the country has comparative advantage, specialization and competitiveness in producing of such product. The figures show that Sudan has zero ( IIS) in the above selected products i.e. it has no comparative advantage in production of such ( IT) products to compete other countries products.

- The above analysis confirms the third hypothesis that There is a significant relation between Sudanese (TI) products and its share in the Balance of trade

\section{Sudanese transformational Industries (TI) strategies and problems}

\section{1 (TI) strategies in Sudan}

Sudan implemented different strategies with respect to (TI) since the beginning of the modern manufacturing sector and the construction of Sinnar damp on blue Nile (in South East of Sudan) in 1925(during colonial regime) to irrigate cotton in Gezira Scheme .

The early stage of this period was dominated by the cotton ginning factories within the Gazira scheme for cotton plantation. Other factories were built for the production of textiles from cotton and edible oil from cottonseeds. The colonial rule encouraged the establishment of some industries as part of a self-sufficiency policy to safeguard against any cutoff of foreign supplies during the World war at that time. The products were serving as import substitutes, relying mainly on local materials for their production. However, these industries were limited in their scale and most of them were established at a rush without proper studies. The quality of the products was poor and the cost of production was high. Therefore, these industries did not survive.

Later few industries were established by foreigners from Syria and Greece to produce sweets, perfumes and soaps. Those industries were neither protected nor subsidized and most of them were nationalized during the 1970s. The policies adopted during the 1990s aimed to remove some of the obstacles that handicapped the flow of the economy by the following measures:

(1) Adoption of free market strategy that aims to reduce public sector control over industrial sector.

(2) Provision of incentives and concessions in different fields like tax and banking services..

(3) Devaluation of the Sudanese currency to match the market price.

(4) Encouragement of the private sector to invest in the (TI).

However, all these measures:-

Failed to generate the expected economic growth for the following reasons:

(A) Were restricted to the structural reform away from addressing the comprehensive macro-economic reform related to the transformational industries (TI) sector.

(B) Were bounded by the limitation of external loans, which led to stresses on demand and increased inflation.

(c) Were devoted to non-genuine activities that hinder transformational industries (TI) to attain high returns.

In the area of policies related to (TI) in Sudan, much attention was paid to the creation of more links with the Sudanese economy to bringing up of new, small and medium sized enterprises that serve other enterprises in Sudan to attain the ultimate goal that is the issue is the creation of income and employment through the multiplier effect. Unfortunately, as we see the small and medium sized enterprises failed to maximize the value of output and did not contribute to productivity growth and employment. This was despite the efforts exerted in the investment promotion, policy of linking Sudanese firms and setting up a credible and comprehensive feedback reporting system that serves both the private and the public sectors. In addition, the industrial development strategy in Sudan gave priority to the rehabilitation of the major industrial areas with respect to improvement of infrastructure such as roads, water supply, and power supply and sewer systems. This strategy also took into consideration the importance of incorporating the environmental dimension into economic development plans. Unfortunately, the relationship between the environmental policies and industrial competitiveness were not been adequately examined. In addition, the National strategies for sustainable development did not consider industry-specific environmental objectives and the amount of time required for achieving them. The strategy had formulated with minimal involvement of industrial institutions and private sector associations and did not specify how industrial sub-sectors and plants would meet environmental objectives. Also in the context of environmental policies the medium and small scale industries represented a collective sources of localized pollution such as organic wastes in water effluent, as well as hazardous wastes, heavy metal sludge, solvents waste ,oils, acidic and alkaline wastes, etc.

In the quadrant-century strategy (2008/2032) a chapter has been devoted to promotion of (TI) through integrity of productive activities, optimum use of resources, improving infrastructure, researches and empowerment of private and 
foreign sectors to invest in (TI)sector to double its contribution in GDP .

In my own view although one third of strategy, which has specified an ample of care of (TI),has passed ,but the strategy not succeeded to increase (TI) contributions in GDP, as it has been unable to improve (TI) infrastructure. While the foreign capital invested in basic industries, the national capital invested in consumptive industries. In addition, the productive sectors strategies contradicted development of related (TI) for example strategy of expansion wheat on behaves of cotton in Gezira hindered edible oil and textile industries.

In addition, I tried to examine the type of manufacturing production adopted in Sudan, but I found that there is no clear policy in this respect, although the traditional Strategy of make -to stock is commonly used.

In my view a lot of businesses have moved away from this traditional Strategy in the recent years to more fluid types of production models like make -to order production Strategy or Assemble to - order Strategy . Because in the traditional Strategy production is based upon demand forecasts, but these forecasts are not always precise, due to an inaccurate read of the economy or unrelated factors that influence consumer demand .

\subsection{The factors that led to minimal economic share of Sudanese (T .Industries)}

a) Factories worked below the full capacity

b) Labor productivity is low due to the poor training and skills.

c) Capital productivity is low due to the working circumstances' of sounding factories.

d) The high cost of production because of high prices of inputs and disruption of factories.

e) Lack of finance and feasibility studies.

f) Problems related to inadequacy of foreign currency, which affect negatively the process of maintenance, imports, \& finance.

g) Changes in policies towards some productive sectors affect negatively the related (TI). The best example is the expansion of wheat cultivation on behave of cotton in Gezira scheme negatively affected edible oil and textile industries

h) There is no clear strategy that able to address the prevailing (TI) problems and at the same time not consider its future development.

Beside the above factors each transformational industries (TI) has its own problems.

As an example:

(1)Leather industry problems:

a) problems related to the quality of animal hides and its processing and handling

b) Problems related to tanning operations.

c) problems of skinning processes

(2)Textile and related industries:

a) Problem of raw material, which is related to the adoption of technology in production \& seed quality

b) Food and beverage industries problems

1) high cost of inputs \& high competition of imported products.

2) Production capacity is low relative to the designed capacity.

3) No clear strategy to connect agriculture with industry ...etc.

Therefore, the above factors and policies participated in the weak share of transformational industries in the economy.

\section{Conclusion}

\subsection{Results}

The findings of this study revealed that (TI) in Sudan did not contribute effectively in supporting GDP this due to its little impact on the industrial value added of products. In addition, TI products not improve exports \& not reduce imports, which led to a negative effect on the balance of trade.

Reference to the above obstacles and unsupportable policies, the Sudanese (TI) economic role has been very marginal.

\subsection{Recommendations}

Eventually the study recommended the following to remedy the (TI) situation 
- The vitality of activating the role of transformational industries and avoid focusing on one kind of industry.

- It is also important to consider the fair distribution of transformational industries among the states and regions and not to concentrate them all in certain areas.

- Priority in erecting (establishing) transformational industries must be given to those areas, which lack such industries.

- Improving of the quality of products is also important through the high quality of inputs, developing of the technology, habilitation (act of making fit), human element and decrease of expenditure in order to promote competitive opportunities.

- The significance of promotion the industrial infrastructure.

- The necessary of adoption investment policies that encourage production and productivity the field of transformational industries.

- The importance of considering mass industries, and not to concentrate only on tiny industries i.e. Adoptions of Big push orientation.

- It is also vital to have financing policies that have easy conditions and encouraging transformational industries.

- Design (TI) Map in Sudan to be consistent with the potential physical and human resources of states

- Formulation of integrated feasibility studies for (TI) projects within the context of each region.

- $\quad$ Policies related to each productive sector should not contradict its related (TI).

- Integration of (TI) with productive sectors and adoption of the industrial clusters (collection of all parts of production process which include producers, importers, marketing channels, centers of finance, technical assistance and producers of complementary products ...etc because such clusters improve the value added and minimize costs and increase quality and facilitate control .

- Adoption of flexible Transformational industries production strategies that take into account the demand and supply side.

- The environmental threats should be taken into account when (TI) are designed.

At the end I think that The field of ( TI) in developing countries, especially in African countries like Sudan need further studies and researches as far as these countries abounds with ample amount of natural resources. The economies of these countries can not benefit from these resources without presence of suitable (TI). The majority of African countries need to scale up its infrastructure investments and improve the business climate $\&$ to take into account all the recommendations that have been mentioned.

\section{References}

African Transformation Report-African center for economic transformation. (2011).

Algorashi, K. (2014). Industrial policies \& development in Developing countries Alerag.

Bakhirma Ahmed Saied-Industrial Economics (2001). -Alzahra for press and distribution Riad SA.

Beacham, A. (1956). Economics of industrial organization, Sir Isaac Pitman and sons p 1 London third edition.

Economic Studies. (2002). Journal second Issue -Algeria.

Guido Buenstorf and Steven Klepper-INDUSTRY CLUSTERS. (2009). THE IMPORTANCE OF 'SPIN-OFF ENTREPRENEURS'R.E.S-April.

Industrial survey Ministry of Industry. (2005).

International Trade Center, UNCTAD/WTO (2009).

Kaldor, N. (1967), Strategic factor in economic development, New York: State School of industrial S

Kamal, D. The role of small scale industries in the development of factors of production -Economies under restructuring period .

Mohamed Mahros Ismail. (1987). Industrial Economics -Egyptian university union -Alexandria -Egypt.

Nimal Sanderatne. (2011). The Sunday Times Economic Analysis-Sunday November 06/2011Sunday November 06.

Rashad, M. A. (1971). Indusrrial project economics -Alnahda Arabian press Cairo Egypt.

The role of transformational industry and structural change UNIDO Report. 
Transformational Map. (2002). Ministry of Industry Sudan.

UNIDO- reports (2009).

World Bank Sudan Report. (2014). Development Indicators.

\section{$(\mathrm{cc}) \mathrm{Br}$}

This work is licensed under a Creative Commons Attribution 3.0 License. 